\title{
UN ENFOQUE DE MERCADEO DE SERVICIOS EDUCATIVOS PARA LA GESTIÓN DE LAS ORGANIZACIONES DE EDUCACIÓN SUPERIOR EN COLOMBIA: EL MODELO MIGME*
}

\author{
MILTON RICARDO OSPINA DÍAZ"* \& PEDRO EMILIO SANABRIA RANGEL"*** \\ UNIVERSIDAD MILITAR NUEVA GRANADA
}

Recibido/Received/Recebido: 06/04/2010 - Aceptado/ Accepted/Aprovado: 31/08/2010

\begin{abstract}
Resumen
El presente artículo aborda el tema del mercadeo en organizaciones de servicio describiendo su desarrollo histórico, situación actual y futuro y enfatizando en la gestión del Mercadeo Educativo en las organizaciones de educación superior, específicamente para el caso de Colombia. Adicionalmente, se muestra la importancia de usar herramientas como la investigación de mercados y el plan de mercadeo en estas organizaciones con el propósito de recopilar valiosa información sobre las tendencias en educación superior, la viabilidad en la oferta de programas académicos, la percepción institucional y el nivel de satisfacción de los estudiantes, docentes, investigadores y administrativos. Este concepto de mercadeo educativo en la propuesta del modelo MIGME, debe posibilitar la mejora de la oferta académica de las instituciones de manera que se ajuste mejor a las necesidades de la sociedad y del sector productivo. Para la elaboración del documento se consultaron diversas fuentes de información secundaria tales como estudios sectoriales, estadísticas y artículos especializados.
\end{abstract}

Palabras clave: Mercadeo educativo, Mercadeo de servicios, Investigación de Mercados, Plan de mercadeo, Gestión educativa.

\section{A MARKETING APPROACH OF EDUCATIONAL SERVICES FOR HIGHER EDUCATION ORGANIZATIONS MANAGEMENT IN COLOMBIA: MIGME MODEL}

\begin{abstract}
This article presents marketing in service organizations describing its historical development, current and future situation, making emphasis in Educational Marketing management in higher education organizations, specifically for Colombia. Additionally, the importance of using tools such as marketing research and marketing plan in these organizations is shown with the purpose to collect information on trends in higher education, the viability in the offer of academic programs,
\end{abstract}

Artículo desarrollado en el marco de las líneas de formación en Organizaciones y en Operaciones y marketing de la Maestría en Gestión de Organizaciones de la Universidad Militar Nueva Granada.

* Administrador de Empresas, Universidad Militar Nueva Granada; Especialista en Mercadeo de Servicios, Universidad Militar Nueva Granada; Especialista en Pedagogía, Universidad La Gran Colombia; Maestría en Gestión de Organizaciones, Universidad Militar Nueva Granada. Profesor de Postgrado y pregrado en el área mercadeo de prestigiosas universidades en Colombia y Consultor en Mercadeo. Correo electrónico: milton_ospinad@hotmail.com

*** Administrador de Empresas de la Universidad Nacional de Colombia; Magíster (MSc) en Administración de la Universidad Nacional de Colombia; Diplôme d'université Sciences de Gestion de la Universidad de Rouen (Francia); Candidato al Doctorado en Ciencias de Gestión de la Universidad de Rouen. Docente Ocasional de Postgrado en varias universidades en Colombia. Docente de planta de la Facultad de Ciencias Económicas de la Universidad Militar Nueva Granada (Bogotá) y actualmente se desempeña como Director de Postgrados de la misma facultad. Correo electrónico: pedro.sanabria@unimilitar.edu.co; pesanabriar@gmail.com. 
institutional perception and satisfaction level of students, teachers, researchers and administrative staff. This concept of educational marketing in MIGME model proposal should make possible to improve institutions' academic offer, in order to adjust better to society and productive sector needs. Various secondary information sources were consulted to develop this document, such as sector studies, statistics and specialized articles.

Key words: Educational Marketing, Service Marketing, Market research, Marketing Plan, Educational management

\title{
UMA ABORDAGEM DE MARKETING DE SERVIÇOS EDUCACIONAIS PARA A ADMINISTRAÇÃO DAS ORGANIZAÇÕES DE ENSINO SUPERIOR NA COLÔMBIA: O MODELO MIGME
}

\begin{abstract}
Resumo
Neste artigose discute o marketing das organizações de serviços. De creve-se seu desenvolvimento histórico, sua situação atual e futura, com ênfase na gestão de marketing educacional em organizações de ensino superior no caso da Colômbia. Além disso, mostra a importância de usar algumas ferramentas; por exemplo, pesquisa de mercado e plano de marketing nessas organizações a fim de coletar informação valiosa sobre as tendências no ensino superior, a viabilidade da oferta de programas acadêmicos, a percepção ins tucional e o nível de satisfação dos alunos, professores, pesquisadores e administradores. No modelo MIGME, este conceito de marketing educacional deverá conduzir a melhorar a oferta acadêmica das instituições para atender às necessidades da sociedade $e$ do setor produtivo. Na elaboração do documento foram consultadas várias fontes secundárias, como estudos setoriais, estatísticas e artigos especializados.

Palavras-chave: Marketing educacional, marketing de serviços, pesquisa de mercado, plano de marketing, administração educacional.

Ospina, M. \& Sanabria, P. (2010) Un enfoque de mercadeo de servicios educativos para la gestión de las organizaciones de educación superior en Colombia: El modelo migme. En: Revista de la Facultad de Ciencias Económicas de la Universidad Militar Nueva Granada. rev.fac.cienc.econ, XVIII (2)
\end{abstract}

JEL: M30, M29, M22.

\section{Introducción}

El presente artículo es el resultado de un proceso de revisión y tratamiento de la información disponible en relación con el tema de la oferta de educación superior en Colombia, comprendida a partir del marco normativo que le sirve de base (Congreso de la República de Colombia, 1992). Este documento pretende contribuir a orientar las políticas de las organizaciones de educación superior para desarrollar la oferta de programas académicos pertinentes, en relación con las necesidades de la sociedad, de los diferentes actores involucrados y del sector empre- sarial, mediante la implementación de un enfoque mercadológico en la gestión de los administradores educativos.

El documento inicia haciendo una breve explicación del concepto de mercadeo y su importancia en la organización, a continuación se hace una reseña del mercadeo de servicios, su rápido crecimiento y sus características y posteriormente se aborda el tema de la educación desde la perspectiva del servicio y se enfoca desde la óptica del mercadeo de servicios. En seguida se muestra el contexto regional y nacional de la educación superior, se exponen las teorías más represen- 
tativas en mercadeo y se explica la forma como puede ser aplicada la mezcla de mercadeo en el caso del sector educativo. Posteriormente se expone la situación del mercadeo educativo en Colombia, se explica la importancia de la investigación de mercados en la gestión educativa y finalmente se presenta la utilidad de diseñar, ejecutar y controlar el plan de mercadeo educativo por parte de las organizaciones del sector.

\section{Mercadeo y organizaciones}

Un primer aspecto a tratar refiere a la importancia del mercadeo en los diferentes tipos de organizaciones, esto en razón de que en el desarrollo de toda actividad comercial, industrial o de servicios, sin importar el tamaño de la organización que allí se desempeña, se requiere "mercadear" los productos o servicios que se derivan de dicha actividad. En este sentido, la gestión de mercadeo es fundamental para la existencia misma de la organización pues es la que puede garantizar el cumplimiento de su función social y económica, de la misma forma, el éxito en las actividades de mercadeo solo puede garantizarse con una adecuada implementación de las estrategias de mercadeo.

No obstante, en el medio académico y organizacional no existe verdadera claridad sobre el concepto de mercadeo, lo cual se puede evidenciar en la confusión existente entre las nociones de mercadeo y ventas o los términos de publicidad y exhibición, entre muchos otros. Por tal razón, en pos de contribuir con la comprensión del tema señalado, por lo menos en lo que se refiere al concepto de mercadeo, es fundamental identificar algunas aproximaciones teóricas que aluden a dicho concepto.

Algunos autores consideran el mercadeo simplemente como una actividad que sirve al proceso de intercambio económico y solo desde una perspectiva empresarial. En esa dirección Ricardo Fernández Valiñas menciona:

"El mercadeo no es una ciencia, porque es una actividad económica que no es comprobable a través de una metodología científica, pues cada empresa, cada país y cada mercado se comportan de diferente manera y de acuerdo a diversas variables; el mercadeo es una actividad que se origina en la economía, pero no es la aplicación práctica de ninguna ciencia, por lo cual tampoco se trata de una técnica; por otra parte el mercadeo tiene actividades creativas, pero la mayor parte de su que hacer se centra en la estadística y la economía por lo que podemos afirmar que tampoco es un arte; por lo tanto el mercadeo es una actividad o conjunto de actividades humanas que tiene como finalidad facilitar el proceso de intercambio entre productores $y$ consumidores para que aquellos puedan obtener utilidad y estos satisfacer sus necesidades" (Fernández, 2002, 11-12)

Por su parte, también en términos netamente empresariales, David Jobber y John Fahy definen el mercadeo moderno como:

"La consecución de los objetivos empresariales mediante la satisfacción y la superación de las necesidades de los consumidores de forma superior a la competencia" (Jobber, 2007, 3).

Así mismo, Peter Druker afirma:

"Que el objetivo del mercadeo consiste en hacer superflua la venta, la finalidad es conocer y comprender al consumidor tan bien que el producto o servicio satisfaga sus necesidades y se venda fácilmente" (Kotler \& Armstrong, 1998).

No obstante, instituciones como la Asociación Americana de Mercadeo "AMA", han ampliado estas nociones, a ámbitos que superan la dimensión empresarial, al definir el mercadeo como:

"El proceso de planificar y ejecutar la concepción, asignación de precios, promoción y distribución de ideas, bienes y servicios para crear intercambios que satisfagan las metas individuales y organizacionales" (Lamb, 2006, 6). 
De acuerdo con las anteriores aproximaciones, en lo empresarial (transaccional) se puede entender la gestión de mercadeo como un intercambio con beneficio mutuo, es decir un conjunto de transacciones entre oferentes y demandantes donde se pretende la satisfacción de las necesidades de los consumidores, mediante los productos o servicios adquiridos, mientras que las organizaciones empresariales obtienen los beneficios económicos que ellas legítimamente pretenden. En ese orden de ideas, el éxito de la gestión de mercadeo estaría dado en la generación de relaciones de largo plazo y la fidelidad absoluta de parte de los clientes siendo el área de mercadeo la responsable de la gestión de las actividades que facilitan el intercambio, con beneficio, entre la organización y el cliente. Esta concepción del mercadeo empresarial se muestra gráficamente (Ilustración 1).

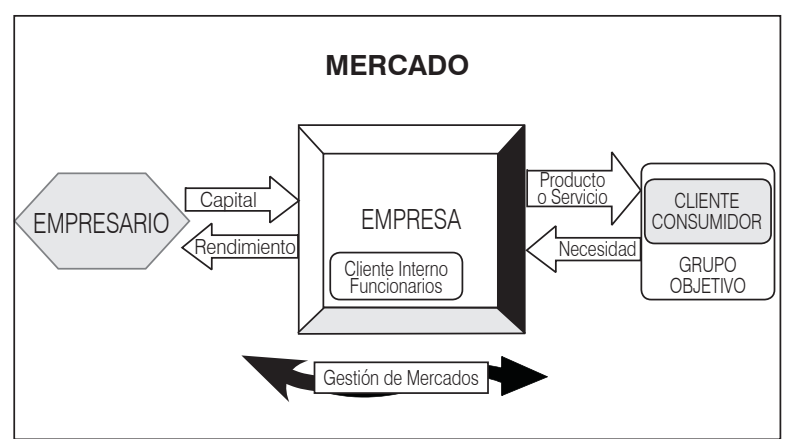

Ilustración 1. Elementos de la gestión de mercadeo empresarial $^{1}$

En ese contexto, los administradores solo le dan relevancia al dinamismo del mercado y a las cambiantes preferencias de los clientes, de tal forma que, trabajan con la premisa de que "la competencia nunca duerme". Dado el competitivo panorama que se presenta, el mercadeo en las organizaciones empresariales se centra solo en los objetivos de: desarrollo de una posición fuerte, rentabilidad, supervivencia y un permanente crecimiento que solo puede ser garantizado mediante el incremento per- manente en el número de clientes o en el volumen de ventas.

No obstante, si se entiende la organización como una unidad social -conjunto de personas- establecida intencionalmente para trabajar con un fin específico (Parsons, 1960)- pero en la cual también existen multiplicidad de intereses- y también como una institución que sirve a los propósitos de de quien la establece -pero también a los fines de sus demás miembros y de la sociedad en su conjunto-, entonces es claro que el concepto de mercadeo no puede establecerse en el simple intercambio económico para la satisfacción de objetivos individuales. Esto es aún más evidente en organizaciones como las que se trabajan en el presente documento: las organizaciones educativas (Ibarra, 2004).

En este sentido, el proceso de mercadeo en las organizaciones consiste no solo en el análisis del mercado y la selección de un segmento atractivo y rentable, en la determinación de un producto que cumpla con los atributos y beneficios que pretenden los clientes individuales o en la determinación del precio adecuado, el diseño de la estrategia de comunicación y la logística de distribución, sino también en la determinación de las necesidades de la sociedad en su conjunto (las necesidades intraorganizacionales, las necesidades de otras organizaciones y las necesidades sociales en general).

En suma, el mercadeo acaba siendo un concepto incluyente que incorpora las nociones de ventas, exhibición, servicio, distribución, publicidad, nicho, fijación de precio, diagnóstico de mercado o actividades facilitadoras del intercambio, entre otras. Pero adicionalmente, trasciende estas perspectivas al tratar de posibilitar la satisfacción de las necesidades de sus miembros y la sociedad en su conjunto, asumiendo entonces una dimensión distinta: la del mercadeo organizacional. Todo ello hace comprensible la trascendencia del mercadeo en términos de una verdadera estrategia en las organizaciones.

$4 \quad$ Elaborado por los autores. 


\section{Mercadeo de servicios}

La concepción del mercadeo de servicios cobra importancia a partir de la década de los años 70's como consecuencia de la situación económica existente en ese momento en los Estados Unidos, dicho periodo se caracterizó por la paulatina transformación de la economía basada originalmente en la producción de bienes hacia otra donde predominan los servicios.

En esta década en Estados Unidos solamente el 55\% de los puestos de trabajo estaban concentrados en el sector servicios mientras que para los años 90’s la cifra ya alcanzaba el 75\%, evidenciándose así un notable crecimiento en términos de la importancia del sector. Por su parte, Europa tuvo un comportamiento similar en los últimos años ratificando la tendencia que señalaba la conformación de una economía basada en los servicios. Jobber hacía referencia a esa cada vez mayor trascendencia del sector cuando afirmaba que:

"El sector servicios sigue ganando importancia. En gran parte del mundo desarrollado su crecimiento ha sido muy rápido y representa entre el 60 y el 70 por ciento del producto nacional bruto de algunos países, superando de lejos el sector de la agricultura y de la manufactura" (Jobber, 2007, 173).

Esta tendencia generalizada hacia el desarrollo del sector servicios transformaría también la forma como se habría de desarrollar el mercadeo. En ese marco general surge el mercadeo de servicios como una noción particular del mercadeo que acompañaría el crecimiento del sector de servicios en todo el mundo.

Junto con el crecimiento del sector, otro factor que contribuyó al surgimiento y desarrollo del mercadeo de servicios fue la desregulación de algunas industrias de servicios como las aerolíneas, el transporte, la banca y las telecomunicaciones, entre otras, generando un aumento en el nivel de competencia en dicho sector y mostrando la necesidad creciente de implementar un enfoque de mercado dentro de estas organizaciones. Asimismo, algunos profesionales como abogados, médicos, contadores y arquitectos, entre otros, empezaron a integrar el mercadeo como parte de la estrategia de difusión de sus servicios profesionales.

Por ello, a pesar de que el concepto central del mercadeo se forjó y desarrolló en el sector de los productos de consumo masivo, posteriormente se evidenciaría la posibilidad de desarrollar el mercadeo para el sector de los servicios. Así, teorías como la famosa mezcla de mercadeo, desarrollada por Borden (1964) y divulgada por McCarthy $(1960,1975)$ como las "4 Ps", se extrapolaron al sector servicios, con gran aceptación, logrando mostrar que el mercadeo de servicios no era sustancialmente diferente al mercadeo realizado para productos de consumo. Philip Kotler, en Estados Unidos, fue uno de los primeros en proponer una ampliación del concepto de Mercadeo hacia el de Mercadeo de Servicios.

De hecho, a partir de 1970 empezaron a aparecen publicaciones que hacían alusión a ese concepto de mercadeo de servicios; autores como Brown J. (1995), L.L. Berry (1983), Pierre Eiglier \& Eric Langeard (1989), Christian Gronroos (1990), Evert Gummesson (1995), Christopher Lovelock (1988) y Lynn Shostack $(1982,1992)$ fueron los pioneros de este nuevo enfoque mercadológico. En síntesis, el mercadeo de servicios puede entenderse como una ampliación, tanto teórica como aplicada, del mercadeo usado para productos para llevarlo hacia la industria de servicios y el cual ha alcanzado altos niveles de desarrollo a medida que pasa el tiempo y el sector servicios se desarrolla.

No obstante, dada las particularidades de los servicios en relación con la producción de bienes, el mercadeo tradicional debe realizar adaptaciones importantes que reflejen esas especificidades. Sin embargo, las adaptaciones señaladas son más de orden conceptual que instrumental pues no requieren modificaciones de las técnicas e instrumentos del mercadeo sino una visión analítica de las implicaciones que tiene el mercadeo en este tipo de organización y, de manera más amplia, en el sector en que se encuentra, de forma que no se asimile al simple intercambio comercial sino, más bien, a la 
satisfacción de las necesidades sociales a través de los intangibles. En esa dirección, Fernández ha evidenciado ya las diferencias entre estos dos enfoques cuando afirma:

\begin{abstract}
"Los servicios se caracterizan porque su comercialización es más compleja que la de los bienes tangibles. Porque el consumidor adquiere el resultado de una actividad humana que no puede percibir de manera inmediata, lo cual genera disonancia, mientras que en los productos tangibles el intercambio es inmediato, es decir el consumidor sabe exactamente lo que compra" (Fernández, 2002, 274).
\end{abstract}

Asimismo, las particularidades señaladas deben llevar también a revisiones del lenguaje propio del mercadeo de forma que se pueda diferenciar tanto el producto del servicio como también el proceso de "producción" de uno u otro. En ese sentido, las palabras producto y servicio, desde un punto de vista etimológico, no poseen el mismo sentido ni las mismas connotaciones ya que el producto se asocia al proceso, acción y resultado de la producción mientras que la palabra servicio se asocia con proceso, acción y resultado de servir. Por ello, ante la carencia de un término equivalente al de producción para expresar el proceso de "fabricación" del servicio, Eiglier \& Langeard han propuesto el neologismo servucción para designar el proceso de creación del servicio (Eiglier, 1989, 3-4).

Entonces, con la consideración de la dimensión conceptual, analítica y lingüística previamente mencionada, se puede señalar que las técnicas e instrumentos del mercadeo de servicios pueden ser los mismos que los usados en el mercadeo de productos. Lo anterior es posible, en cuanto, los compradores, tanto de productos como de servicios, actúan movidos por motivaciones psicológicas y sociológicas similares: seguridad, confort, aceptación, etc. De esta manera, las técnicas propias de la venta de productos de consumo puedan adaptarse para la oferta de servicios de salud, servicios financieros, servicios de recreación o servicios académicos, entre otros, con la salvedad de que las necesidades sociales que ellos satisfacen son de otro orden -no material- (salud, financiación, esparcimiento y educación, entre otras).

Por tanto, entendiendo que el mercadeo de servicios es una ampliación del concepto tradicional, se puede afirmar que este tipo de mercadeo desarrolla entonces los mismos procesos de intercambio con beneficio mutuo, entre consumidores y organizaciones, pero con el objetivo final de satisfacer las demandas y necesidades de los usuarios que no están asociadas a bienes de consumo. Por otro lado, mientras el mercadeo de servicios desempeña este papel, debe realizar también una amplia consideración de las características intrínsecas de la organización, de las necesidades de sus miembros, de los requerimientos del sector económico en que se encuentra y sobre todo, de los requerimientos de la sociedad en su conjunto.

\section{La educación como un servicio}

Como es sabido, la educación es uno de los pilares fundamentales del desarrollo de cualquier sociedad. Así, la educación superior tiene como función principal la formación de ciudadanos íntegros que sirvan al desarrollo de las organizaciones y la sociedad en general; en ella se debe fomentar la construcción de conocimiento (docencia) y la investigación científica (investigación) que generen impactos positivos en la sociedad y permitan la identificación de oportunidades para el desarrollo regional o nacional y para el beneficio de la comunidad (extensión - proyección social). Por supuesto, como parte de las múltiples dimensiones sociales, la universidad también debe ser el motor de desarrollo económico de las naciones, pero con la salvedad de que dicho desarrollo, y el conocimiento asociado a este, tenga sentido en términos de su apoyo al avance social y cultural de los pueblos y a su contribución en la reducción de las brechas sociales.

Esta orientación de las políticas en materia de educación se expresa en los documentos marco que orientan la acción educativa de las naciones. Para el caso colombiano, estos lineamientos están establecidos en la "Agenda de Políticas y Estrategias para la Educación Superior Colombiana 2002 - 2006: De la Exclusión a la Equidad" (ASCUN, 2007), en 
el documento denominado "Revolución educativa" (MEN, 2002), en el "Plan Decenal de Educación 2006-2016" (MEN, 2006a), en el análisis denominado "Visión Colombia II Centenario: 2019" (Presidencia de la República) y en el documento "2009 Año de la Educación para la Innovación y la Competitividad desde la Pertinencia” (Rincón, 2009).

En estos documentos se coincide en definir la educación como:

"Un proceso de formación integral, pertinente $y$ articulado con los contextos local, regional, nacional e internacional que desde la cultura, los saberes, la investigación, la ciencia, la tecnología y la producción, contribuye al justo desarrollo humano, sostenible y solidario, con el fin de mejorar la calidad de vida de los colombianos, y alcanzar la paz, la reconciliación y la superación de la pobreza y la exclusión" (MEN, 2006a, 16).

Por todo ello, se entiende que la formación académica debe permitir tanto la construcción y el acceso al conocimiento como también la confrontación con la realidad del contexto, la generación de pensamiento crítico, el mejoramiento de la calidad de vida de los estudiantes, el desarrollo de la sociedad y la construcción de un mejor futuro individual y colectivo (Juliao, 2005).

En ese orden de ideas, la educación per se tiene la connotación de un servicio por el papel que tiene dentro de la sociedad en su conjunto y por su rol en la satisfacción de necesidades no asociadas a bienes tangibles. Por otra parte, la Educación, al presentar las mismas características de los otros servicios, es decir, su intangibilidad (no puede verse, saborearse ni tocarse), que su fabricación y consumo se dan de manera simultánea, que una vez generado es irrepetible y que no se puede almacenar, entre otras, entonces puede ser comprendida también como un servicio.

Entonces, si la educación es entendida como un servicio fundamental de orden público, en cuanto su objetivo es servir a las necesidades de formación social, la labor de la enseñanza requiere de un eficiente sistema educativo que responda a las necesidades de formación señaladas (que no solo refieren al sector productivo) mediante un enfoque que dé respuesta a las exigencias socioeconómicas, políticas, culturales y legales de la sociedad (pertinencia). En ese sentido, el sistema debe responder a las necesidades y expectativas del ser humano, formándolo en el desarrollo de competencias para la vida, articulándolo con el contexto local, nacional y global y permitiéndole la movilidad y la formación integral en ese "entorno democrático, pacífico y globalizado" que el plan decenal propone para el caso colombiano.

En ese orden de ideas, para que se logre la consolidación de un sistema educativo que responda a las necesidades sociales ya señaladas, dicho sistema debe acudir tanto a la gestión del mercadeo, y específicamente del mercadeo de servicios, como a los conceptos e instrumentos propios de este para acomodar su oferta académica y sus demás acciones formativas a las demandas sociales existentes. En la misma lógica, el mercadeo educativo (como parte del mercadeo de servicios) es fundamental como modelo de gestión para alcanzar los propósitos que la sociedad ha planteado para la educación.

En síntesis, la pertinencia de este servicio fundamental, que tanto se menciona dentro del sistema educativo, consistiría en acercar cada día más al sistema y sus organizaciones educativas a lo que el país necesita y espera de la educación. Para ello, el mercadeo educativo es pieza clave para identificar las demandas sociales enunciadas y señalar los propósitos y objetivos que debe perseguir la organización educativa en el contexto en el que se desarrolla.

\section{Contexto regional y nacional del servicio educativo: la educación superior}

Se ha señalado que la educación tiene un papel fundamental en el desarrollo de la cultura, la innovación, el desarrollo tecnológico y la transferencia de conocimiento (todos ellos factores de la tan deseada competitividad de las naciones). No obstante, la educación se ha venido desarrollando, en muchas 
ocasiones, de manera descontextualizada y desintegrada de las otras instituciones de carácter social. Por ello, si la competitividad de un país estuviera dada por su capacidad de producir bienes y servicios que satisfagan la demanda de los mercados nacionales $e$ internacionales y a la vez impacten positivamente en los niveles de ingreso y la calidad de vida de su población, estos factores competitivos deberían ser propósitos conjuntos y sinérgicos de todas las instituciones sociales: el Estado, el sistema educativo y las organizaciones, entre otros.

Como parte de ese propósito de construcción colectiva, es necesario el desarrollo de programas académicos que respondan a las necesidades específicas de cada país y sus organizaciones, al igual que de programas de extensión e investigación que generen impactos reales en términos de dichas necesidades (incluido el acceso a la educación -cobertura- y la diversidad de conocimientos -oferta-). Lo anterior, ya está siendo reconocido por el sistema educativo de los países con mayor nivel de desarrollo, y también con mayor reconocimiento internacional de sus instituciones educativas en función del cumplimiento del rol social mencionado. Sin embargo, en los países con un nivel de desarrollo menor no se sigue esta tendencia, por el contrario, el sistema educativo en los países latinoamericanos pareciera no contribuir con la reducción de las brechas sociales y si con la desarticulación de las acciones nacionales.

Por ejemplo, la tasa promedio de analfabetismo en Latinoamérica se mantiene en niveles muy altos frente a otras regiones del mundo. En ese sentido, según el informe presentado por Euromonitor, la tasa de alfabetización en la región apenas alcanzó el $92,2 \%$ en el año 2009 a pesar de que ha tenido un mejoramiento de trece puntos y medio desde el año 1980 y a pesar de la mayor inversión en educación de los gobiernos de la región. Por su parte, para el caso de Colombia, la tasa de alfabetización en este mismo periodo pasó del 70,1\% al 94,1\% a pesar de que su inversión educativa se elevó un 7,4\% anual entre los años 1990 y 2009 (Portafolio, 2010).

En ese sentido, aunque Euromonitor International señala que esta mayor inversión en educación ha generado una generación de profesionales altamente cualificados y ha contribuido en atraer mayor inversión extranjera, la inversión realizada en educación aún es todavía muy baja comparada con el de los países con mayor nivel de desarrollo.

Por ello, dado que la inversión en educación trae como consecuencia el mejoramiento de la calidad del capital humano, la mejora en los ingresos per cápita, el crecimiento económico y la disminución de la pobreza, se hace necesario que las naciones con menor nivel de desarrollo económico realicen un esfuerzo adicional y que las universidades, a través de los programas académicos que desarrollan, se transformen en un enlace real entre las ideas, el conocimiento y el talento de los estudiantes y las necesidades de la industria, las organizaciones y el gobierno.

Este reconocimiento al sistema educativo, que podría reflejar también la diferencia en términos del desarrollo económico, social y cultural, se puede ver reflejado en indicadores como el Ranking Mundial de Universidades, que en el año 2009 ubica solo 14 universidades latinoamericanas dentro de las primeras 500 a nivel mundial. En esta estadística latinoamericana encontramos diez (10) universidades de Brasil, dos (2) de México, una (1) de Chile y una (1) de Argentina mientras que la primera universidad colombiana -Universidad Nacional de Colombia- aparece en el puesto 594 (Webometrics, 2009). En ese sentido, este fenómeno podría estar contribuyendo con el rezago, en términos de formación y conocimiento, entre los países del "primer mundo" y del resto de naciones.

En lo que concierne a Latinoamérica la tendencia de la educación superior se orienta hacia el fortalecimiento de los programas de postgrado, en especial maestrías y doctorados, como una estrategia para impulsar la investigación y la construcción de conocimiento en pos de mejorar los indicadores de competitividad en el concierto regional y mundial. No obstante, a pesar de este loable propósito, aún no se ha logrado una verdadera integración entre la educación que se imparte y las demandas sociales y organizacionales de nuestros países de tal forma que las instituciones educativas se puedan constituir 
en un punto de apoyo para llevar a los países de la región hacia la denominada sociedad del conocimiento (Castells, 1997).

Asimismo, en la región también es notoria la tendencia de fortalecer la educación técnica y tecnológica, que forma parte del sistema de educación superior, de manera que pueda asumir un doble propósito, a saber, el de modificar la estructura de la matrícula en los diferentes programas, hoy concentrada en carreras de larga duración, y el de formar el personal de técnicos y tecnólogos que requiere el sector productivo (Gazzola, 2008). Sin embargo, este énfasis parece desconocer la formación para la vida (personal y social) para centrarse exclusivamente en las demandas de solo un tipo de organización social: la empresarial.

En el caso de Colombia la situación no es muy distinta, el servicio público de Educación Superior es impartido por organizaciones privadas y también por otras de carácter público (cada vez menos y con mayores limitaciones), que ofrecen un sinnúmero de programas académicos en distintas áreas del conocimiento pero con problemáticas tan serias como las que se han señalado hasta ahora: absoluta desarticulación con las necesidades de la sociedad en su conjunto, pero también con los requerimientos del sector productivo (MEN, 2009); según la ministra Vélez White, dicho proceso de articulación está en sus fases iniciales liderado principalmente por el SENA y con alianzas estratégicas entre las Instituciones de Educación Superior IES e Instituciones de Educación Media y el sector productivo y está basada en:

"La revisión de currículos (entre sector productivo, instituciones de educación media y superior), la conformación de equipos interdisciplinarios e interinstitucionales, la optimización de recursos y medios educativos haciendo uso de laboratorios y talleres de las instituciones, la inversión en conectividad y recursos tecnológicos, y la obtención por parte de los estudiantes de su certificación laboral" (MEN,2009).
Como factores claves de la articulación con el sector productivo y entre las diferentes organizaciones educativas (aunque deja de lado la necesaria articulación con otro tipo de demandas sociales). En términos de las cifras relacionadas con la cobertura en educación superior en Latinoamérica, como un indicador de respuesta a las necesidades sociales de formación, las estadísticas del Ministerio de Educación Nacional de Colombia -MEN- en cuanto al sector educativo nos muestran que el logro más significativo del país ha sido el de incrementar la cobertura del $20.8 \%$ al $24.6 \%$, alcanzando la cifra de 1.212.037 estudiantes en este nivel educativo; sin embargo, Colombia en el 2005 mostró una cobertura inferior a la que presentaron en el 2003 varios de los países latinoamericanos con desarrollo similar como es el caso de Argentina que llegó aproximadamente al 60\%, de Panamá que alcanzó el $51 \%$, de Chile con un 47\%, de Costa Rica con el $44 \%$, de Venezuela en un $43 \%$, de Uruguay con un 41\%, de Bolivia con el 38\%, de República Dominicana con $37 \%$, de Perú con el 34\% o de Cuba con un $34 \%$ de cobertura. No obstante el último censo mostró un aumento mayor al 10\% pues la cifra es del 27.7\% de cobertura para la población entre 18 y 24 años (MEN - DANE). Para el 2009 la cifra se sitúa en un 35.5\% (Observatorio Universidad Colombiana) lo cual muestra un avance paulatino en este indicador.

En lo que se refiere a la amplitud de la oferta académica, manifestada en la diversidad de graduados en las diferentes áreas del conocimiento, la cifra de graduados en Colombia en el período comprendido entre 1960 -2004 se puede describir de la siguiente manera: se han graduado 408.130 profesionales en Administración (19\%), 386.659 en Educación (18\%), 150.836 en Derecho (7\%), 149.577 en Contaduría Pública (7\%), 118.239 en Ingeniería de Sistemas (6\%), 75.630 en Economía (4\%), 71.444 en Ingeniería Industrial (4\%), 70.139 en Medicina (3\%), 62.490 en Ingeniería Civil (3\%), 57.266 en Arquitectura (3\%) y otras profesiones (27\%) (MEN - Observatorio Laboral) mostrando una gran concentración de profesionales en muy pocas áreas del conocimiento: administración y educación, lo cual evidenciaría la limitada respuesta a las múltiples demandas de formación que la sociedad posee. Por 
supuesto esta situación, en relación con la oferta académica, se genera como respuesta a las demandas realizadas por parte de aquellos que aspiran a ingresar a la educación superior y que paulatinamente son quienes terminan determinando los programas ofrecidos por el sistema educativo, aunque esta oferta formativa no siempre corresponda con los requerimientos de la sociedad en su conjunto.

Por otro lado, en lo que se refiere a la posibilidad del sistema educativo nacional para reducir las brechas sociales, según las estadísticas solo se puede mostrar un leve incremento en el número de matriculados dentro de universidades de carácter oficial $y$ privado lo que significa tan solo un crecimiento promedio anual aproximado de 3\% entre el año 2000 y el 2008 (Tabla 1). Según el Ministerio de Educación en términos generales:

"El país ha avanzado en su meta de ampliar la cobertura de la educación superior, pero para cerrar la brecha entre las posibilidades de acceso de las personas de menores ingresos y las de los estratos más altos, y responder con una fuerza laboral cada vez más calificada a las exigencias de los mercados modernos, los esfuerzos deben ser mayores" (MEN, 2006b).

Por lo anterior, es prioritario continuar concentrando los esfuerzos en la población de menores ingresos y en generar acceso a una educación superior pertinente para toda la población del país.

Así mismo, las brechas sociales que ya se han señalado pueden haberse ampliado en cuanto se refiere a la posibilidad de la población de acceder a la Educación Superior dado el aumento constante en los costos educativos. En tal sentido, el costo educativo promedio de la Educación Superior se ha estado incrementado constantemente por encima del porcentaje de aumento del salario mínimo en Colombia, con lo cual cada vez es más difícil para la población en general asumir dentro de sus ingresos el costo asociado a la matrícula universitaria. Lo anterior se hace evidente si se considera que el índice de costos de la Educación Superior privada ha tenido un crecimiento promedio anual del 7.63\% (variación anual periodo comprendido entre 1999 y 2009) (DANE, 2010a) mientras que el Índice de Precios al Consumidor - IPC ha tenido un crecimiento promedio anual de 6.3\% (en el mismo periodo analizad) (DANE, 2010b).

Tabla 1. Cobertura de la Educación Superior en Colom$\mathrm{bia}^{2}$

\begin{tabular}{|l|r|r|c|}
\hline \multicolumn{1}{|c|}{ Año } & $\begin{array}{c}\text { No } \\
\text { alumnos }\end{array}$ & Cobertura & $\begin{array}{c}\text { Variación frente } \\
\text { al año anterior }\end{array}$ \\
\hline 2000 & 934,085 & $13.82 \%$ & $+0.37 \%$ \\
\hline $2001(1)$ & $\begin{array}{r}977,243 \\
1,000,148\end{array}$ & $20.9 \%$ & \\
\hline $2002(2)$ & $1,050,032$ & $25.6 \%$ & $+4.70 \%$ \\
\hline 2004 & $1,113,726$ & $26.9 \%$ & $+1.30 \%$ \\
\hline 2005 & $1,212,037$ & $28.9 \%$ & $+3.00 \%$ \\
\hline 2006 & $1,301,728$ & $30.6 \%$ & $+1.70 \%$ \\
\hline 2007 & $1,359,828$ & $31.8 \%$ & $+1.20 \%$ \\
\hline $2008(4)$ & $1,444,544$ & $33.3 \%$ a $34.1 \%$ & $+1.50 \%$ \\
\hline $2009(5)$ & $1,570.477$ & $35.5 \%$ & \\
\hline
\end{tabular}

En cuanto a los programas de postgrado en Colombia es de resaltar el incremento constante desde el año 2003 de la inscripción de estudiantes en programas de maestrías y doctorados con un crecimiento del $31.3 \%$ y $70.0 \%$ respectivamente para el año 2003; $16.05 \%$ y $28.91 \%$ para el año 2004 y para el año 2005, del 14.31\% y 19.95\%. La oferta de programas de Maestría y Doctorados aumentó en el 2003 en un 26\% y 31\%, respectivamente, Asimismo, en el año 2006 se presentó otro aumento significativo en la oferta de Doctorados en un 28\%. En conclusión, el país pasó de 31 pro-

5 FUENTE: Observatorio de la Universidad Colombiana. 
gramas de Doctorado en el 2001 a 60 programas en el año 2006, cifra que sigue siendo muy baja en el concierto de la Educación Superior de los países latinoamericanos, ya que el número de doctores graduados por millón de habitantes apenas llega a 1.1 en Colombia, mientras que en Argentina, Brasil, Francia y Estados Unidos es, en su orden, de 9, 19, 140 y 177 por cada millón de habitantes (MEN, 2006b).

Por otro lado, entre los años 2002 y 2008, el Gobierno Colombiano ha brindado apoyo a 8.258 profesionales para que realicen estudios en programas de maestría y doctorado, dentro y fuera del territorio nacional (Universia, 2010). Así mismo, recientemente se evidencia una tendencia creciente en el número de programas de formación doctoral en el país según se muestra en un estudio del Ministerio de Educación, Colciencias y el CNA que señala que:

"A diciembre 31 del 2007 existían 92 programas de doctorado en Colombia, distribuidos en 22 universidades y de los cuales se han graduado un total de 584 doctores hasta la fecha del mencionado estudio (diciembre del 2007). De estos, 88 se graduaron antes de 2000, los otros 496 se graduaron entre el 2000 y el 2007, por lo tanto se trata de doctorados bastante recientes..... Es interesante resaltar que en los últimos dos años (2006 y 2007) se han graduado más de 100 doctores por año (108 en el 2006 y 102 en el 2007), lo cual es una cifra mayor a la que se estaba estimando en el país. Sin embargo, esta cifra de doctores graduados por año es muy baja si la comparamos con el nivel de formación doctoral que han alcanzado países como Chile (600 por año), México (2.700 por maño) y Brasil (más de 11.000 por año)" (Consejo Nacional de Acreditación).

En referencia a los diferentes niveles de formación en el país se puede señalar que el número de graduados de la educación superior para el período comprendido entre los años 1960 y 2004 se distribuye de la siguiente manera: en el país existen
2.132.744 profesionales en los diferentes núcleos básicos de conocimiento. De éstos, 1.398 .352 corresponden al nivel universitario (65.6\%); 468.379 al nivel de técnico profesional y tecnológico (22\%) y 266.013 al nivel de postgrado (12.5\%) donde las especializaciones representan un (11\%), las Maestrías (1\%) y los Doctorados (0.01\%) (MEN - Observatorio Laboral). En resumen, la información presentada previamente, así como la que otras fuentes pueden suministrar (Educación Compromiso de Todos), muestra con claridad que el servicio educativo en Colombia parece incapaz de responder a las demandas de la sociedad y a diversas necesidades de sus miembros en cuanto se encuentra desarticulado de otras organizaciones y del estado, desarrolla sus funciones de docencia e investigación sin impactar en el medio social (en términos de la satisfacción de necesidades y la reducción de las brechas sociales), se desenvuelve al margen del contexto internacional (por el poco reconocimiento de sus instituciones educativas), se encuentra orientado más a la formación técnica para el trabajo que para la vida, limita el acceso de la población de menores recursos (por los altos costos), presenta índices muy bajos en términos de cobertura en general, se encuentra concentrado en un número limitado de áreas del conocimiento al igual que en limitadas áreas geográficas (grandes ciudades) y presenta poco desarrollo y baja cobertura en los programas de formación avanzada de postgrado.

\section{La educación superior y el mercadeo de servicios educativos}

Tradicionalmente las organizaciones de carácter educativo se desarrollaron en un medio estable $y$ protegido durante mucho tiempo, sin embargo, en los últimos años el entorno se ha transformado dramáticamente llevando también a cambios significativos en el tipo de formación que la sociedad demanda del sistema educativo. Las condiciones actuales del país relacionadas con la crisis económica, el desempleo, el álgido ambiente político y las demás problemáticas sociales, entre otras, ha mostrado la necesidad de que los administradores de las organizaciones educativas respondan mercadológicamente a esos cambios contextuales. 
Adicionalmente, ante la diversidad de programas $y$ organizaciones educativas existentes, cada una de ellas requiere mecanismos de divulgación que les permita transmitir las particularidades de sus instituciones, su orientación académica, el soporte institucional existente, las acciones de investigación que desarrolla, su enfoque pedagógico, el tipo de impacto social que pretende lograr, el tipo de profesional que busca formar, etc., es decir, requiere instrumentos que permitan dar a conocer a la sociedad su sello institucional. Este podría ser, de hecho, el propósito fundamental del mercadeo de servicios aplicado al sector educativo.

Por otra parte, si se tiene en cuenta un enfoque de orden más comercial que académico (lo cual no es propio de las organizaciones educativas), la exacerbada ideología sobre el ambiente competitivo aunada a la creciente exigencia de parte de los clientes o usuarios hacia las diferentes organizaciones, en términos de la calidad del servicio y la plena satisfacción de sus necesidades, han generado en ellas una presión creciente en cuanto a su existencia se refiere. En ese mismo sentido, la presión del mercado podría estar incrementando en las organizaciones educativas la necesidad de orientar sus esfuerzos hacia el diseño de estrategias encaminadas a la diferenciación de la institución y sus programas académicos, la mejora de la calidad de los servicios prestados, el desarrollo de ventajas comparativas y el diseño de planes de comunicación para la promoción y difusión de su imagen institucional.

También desde este segundo enfoque, Caetano manifiesta como:

"La educación del nuevo siglo busca incesantemente nuevas respuestas para los desafíos que se le presentan. El cambio vertiginoso de la sociedad de nuestros días, hace que los servicios de educación buscan maneras para ser más competitivos. Las instituciones de enseñanza frecuentemente encuentran dificultades para mantener la lealtad de sus clientes frente a numerosos factores concurrentes como las características innovadoras de nuevos cursos, mejores instalaciones, disponibilidad e innovaciones tecnológicas aplicadas al sector" (Caetano, 2003).

No obstante, ya sea por las razones expresadas inicialmente (académicas) o por razones de mercado, con el paso del tiempo las instituciones educativas han tenido que tomar conciencia de que, en su condición de organizaciones de servicios, deben adaptar su oferta académica a la satisfacción de las necesidades educativas y a los requerimientos de la sociedad y del sector productivo para asegurar así su sustentabilidad y desarrollo. Todo ello hace explícita la necesidad de identificar las nuevas demandas sociales y organizacionales que nuestros países presentan ya sea en términos de formación, de investigación o de impacto social.

En consecuencia, actualmente varias organizaciones de educación superior han empezado a trabajar con enfoque de orientación al usuario y a implementar el uso de técnicas de mercadeo, tales como la investigación de mercados, la inteligencia de mercados, el geomarketing, etc., con el objetivo de indagar sobre las necesidades del entorno en relación con los programas educativos, analizar los gustos, expectativas y satisfacción de los estudiantes actuales o potenciales con respecto a aquellos, estudiar la percepción de la comunidad académica sobre infraestructura, bienestar universitario, convenios interinstitucionales, prácticas empresariales, entre otras variables. Esta forma de actuar, desde las demandas sociales, debe llevar también a las demás organizaciones de educación superior a adaptar la oferta académica a las condiciones contextuales ya señaladas y de esta forma lograr los objetivos que el sector educativo propone. Las particularidades de este modelo de gestión de mercadeo educativo se evidencia a continuación (Ilustración 2) y muestra los diversos elementos que deben considerarse en él para respetar la esencia de la organización educativa en términos de su función social, su categoría de organización de servicios y su condición de servicio público.

No obstante, a pesar de los progresos existentes a nivel mundial y regional, en Colombia el mercadeo aplicado a los servicios educativos no es ampliamente utilizado por las directivas académicas de las 


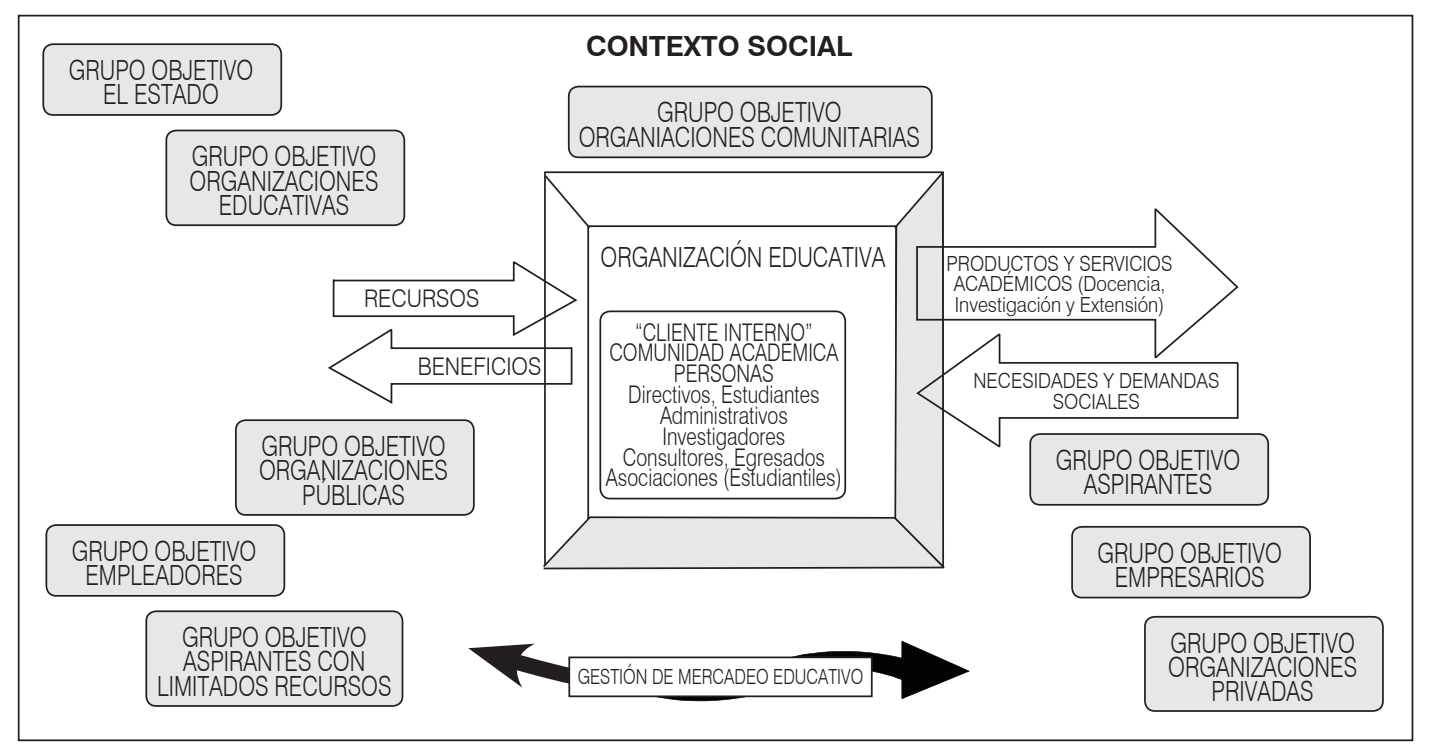

Ilustración 2. Elementos de la gestión de mercadeo en organizaciones educativas ${ }^{3}$

diferentes organizaciones educativas -colegios, institutos o universidades públicas y privadas- (Ospina, 2006) debido a que sus beneficios son prácticamente desconocidos en relación con el crecimiento organizacional, la reducción de deserción académica, la difusión de la imagen y valores institucionales, el reconocimiento social, la diferenciación de los programas académicos y el fortalecimiento del sentido de pertenencia de estudiantes, docentes, investigadores y administrativos, entre otros.

De hecho, como consecuencia de la ya mencionada estabilidad, hasta hace varios años las actividades de mercadeo educativo en nuestro país eran casi nulas, sin embargo, a medida que pasó el tiempo, el surgimiento de nuevas organizaciones educativas en Colombia ha generado mayor variedad y en algunos casos, mayor calidad en el portafolio de programas y servicios académicos que se ofrecen. Todo ello ha producido una multiplicidad de opciones en materia de ofertas educativas que deberían haber generado la inquietud de trabajar desde una perspectiva de mercadeo de servicios. En adelante, la considera- ción de todas las alternativas y potencialidades del mercadeo de servicios será la que le permitirá a las organizaciones de educación superior del país mantenerse en el medio e incidir en la sociedad a partir de sus propios principios y valores institucionales.

Por otra parte, si las organizaciones de educación superior en Colombia desean contribuir con el cumplimiento de las metas nacionales en materia de cobertura, calidad y pertinencia de la educación superior, en los términos ya señalados, es imprescindible que empiecen a trabajar con una orientación mercadológica que les permita articularse con las políticas del estado en materia educativa y con los requerimientos de las demás organizaciones sociales y productivas.

En consecuencia, algunas organizaciones educativas en nuestro país han empezado a tomar conciencia de la importancia de la gestión de mercados dentro de su direccionamiento estratégico. En esta dirección, deberán empezar a hacer uso del mercadeo para el diseño de sus estrategias de posicio-

3 FUENTE: Elaborado por los autores. 
namiento, segmentación y diferenciación de forma que puedan orientar sus acciones institucionales a las diversas demandas, a saber, sociales, de mercado, de formación, del sector productivo, de la sociedad y de los empleadores (en materia de profesionales íntegros y con las competencias requeridas). Por tanto, el desconocimiento de un enfoque de mercado por parte de una organización de carácter educativo implica estar desarticulado tanto de las necesidades sociales y educativas del grupo objetivo como también de las otras instituciones sociales y por consiguiente, por fuera del marco de calidad requerido para la educación (MEN, 2003), (Congreso de la República, 2008).

Finalmente, en esa necesaria orientación de las organizaciones de educación superior hacia la sociedad y el contexto, tanto la investigación de mercados como la demás técnicas de mercadeo (mercadeo estratégico, publicidad, relaciones públicas, mercadeo directo, etc.) se constituyen en instrumentos de gran ayuda tanto para la evaluación del medio como para el diagnóstico y la acción de las propias instituciones educativas de tal forma que se garantice la pertinencia de la oferta académica, se facilite la divulgación de los logros institucionales (en materia de producción científica e investigativa, acciones de proyección social, procesos de acreditación, impacto de los egresados en el medio, entre otros) y se realice la promoción de sus condiciones institucionales, orientación pedagógica, eventos académicos, etc.

\section{Del mercadeo de servicios al concepto de mercadeo de servicios educativos: propuesta de un modelo de gestión de mercadeo educativo}

Como se señaló en un aparte anterior, en mercadeo existen diversas teorías que pueden ser aplicadas a los diferentes tipos de organización, de forma que cuando esta importante función se realiza sobre una organización dedicada a la prestación de servicios, de cualquier orden, se origina la noción de mercadeo de servicios. En ese tránsito del mercadeo de productos al mercadeo de servicios se ha pasado del enfoque de las "Cuatro P's" de McCarthy en el año 60 (Producto, Precio, Plaza y Promoción) a enfoques como los presentados por Eiglier y Langeard (1989), Kotler (1999) y Fernández (2002).

En esa transición mencionada, también se han planteado otros acercamientos que median entre una perspectiva basada en los bienes (tangibles) y una perspectiva basada en el servicio (usuario). Este es el caso del abordaje alternativo realizado por Phillip Kotler, con base en los planteamientos realizados por Lauterborn ${ }^{4}$ (1990), a la temática tradicional de la mezcla de mercadotecnia al proponer:

"La conveniencia de cambiar las 4 Ps del vendedor (empresa), por las 4 Cs del cliente. Es decir cambiar un enfoque de transacción a uno de relación con el cliente. En este cambio el centro de atención ya no es el producto sino el cliente. No nos enfocamos en un precio de venta, sino en cuál es el coste de adquisición para el comprador. Cambiamos de distribución y ventas a comodidad de acceso al servicio; esta opción nos llevará a una gran variedad de canales. Ya no hablaremos mas de Promoción, ahora tratamos de crear una comunidad; una relación directa y de confianza con el cliente que nos lleve a fortalecer los lazos de comunicación y por ende a acelerar las ventas" (Merk2, 2), (Kotler, 1999).

De esta forma es posible la generación de un modelo con las variables modificadas que se mencionan a continuación:

- De la p de Producto a la noción de Cliente: En esta perspectiva pierde importancia el interés y voluntad exclusiva de la organización

4 Lauterborn planteaba la necesidad de pasar del enfoque de Producto (Product), Precio (Price), Plaza (Place) y Promoción (Promotion) a las 4 Cs de Customer needs and wants (Necesidades y deseos de los clientes), Cost to the user (costo), Convenience (Conveniencia) y Communication (Comunicación). 
y se le da absoluta relevancia a las necesidades y deseos de los clientes. Una vez consultadas las necesidades del cliente se procede a "elaborar" un producto o servicio que responda a estas necesidades.

- De la p de Precio a la noción de Costo: Esta aproximación no se hace hincapié en el precio del producto o servicio que la organización ofrece sino que se busca reducir aquellos costos que el cliente debe asumir por el hecho de comprar el producto o servicio señalado de manera que se pueda facilitar el acceso económico al bien o servicio. En ese sentido, se considera no solo el valor a pagar por el bien o servicio demandado sino el costo asociado a la compra misma.

- De la p de Plaza a la noción de Conveniencia o Comodidad: Aquí ya no se considera trascendental el lugar físico donde se realiza el proceso de compra (distribución y ventas) sino que se trata de determinar la forma como se puede facilitar el acceso material del cliente al bien o servicio ofrecido. De esta forma se le genera al cliente mayor comodidad para el acceso y se responde mejor a sus requerimientos.

- De la p de Promoción a la noción de Comunicación y Comunidad: Desde este enfoque no se pretende invadir la percepción del cliente con mensajes generalizados sino hacerle llegar solo la información que él individualmente requiere. Se trata de remplazar los mecanismos unidireccionales de comunicación (información) por unos donde exista una comunicación de doble vía (comunicación real), es decir, unos mecanismos de comunicación que retroalimenten a la organización de las necesidades, expectativas y percepciones del cliente. Se trasciende de la mera transacción comercial para establecer una relación directa que genere confianza entre la organización y los clientes y entre la organización y la comunidad en general.

Por otra parte, en este caso específicamente para los servicios, Bernard Booms y Mary Bitner también habían planteado una aproximación alterna- tiva al modelo tradicional de "Cuatro P's" al desarrollar un modelo ampliado de "Siete P's" en cuyo despliegue incorporan tres nuevos elementos: Personas, Procesos y Evidencia física (Phisical evidence) de la siguiente manera (Booms y Bitner, 1981, 47-52):

- El elemento Personas se refiere a los grupos de individuos involucrados en la prestación del servicio, es decir, los directivos, empleados y consumidores, entre otros.

- Los Procesos apuntan al encadenamiento de las actividades que hacen que el servicio pueda llegar hasta el cliente.

- La Evidencia física se centra en el ambiente intangible y tangible en que el producto o servicio es suministrado.

No obstante, como se ha hecho evidente, la mayoría de modelos mercadológicos que se han desarrollado, tanto en referencia a productos como a servicios, han tomado como referencia el modelo divulgado por McCarthy. Por ello, a pesar su antigüedad y su sencillez, este enfoque todavía puede ser considerado como un modelo vigente y de gran utilidad analítica por su fácil recordación, su gran efectividad y la similitud con otros modelos existentes -como el de las $4 \mathrm{C}^{\prime} \mathrm{s}$-. Adicionalmente, este modelo tiene la gran ventaja de ser fácilmente adaptable al producto o servicio de cualquier tipo de organización y por tanto puede ser considerado como un modelo holístico, generalizable, adaptable y de gran provecho para ser aplicado en cualquier sector, en este caso, en el mercadeo educativo.

En ese orden de ideas, Edgar Enrique Zapata ha realizado una adaptación de las $4 \mathrm{P}^{\prime} \mathrm{s}$ del mercadeo para el caso de la gestión en las organizaciones educativas, poniendo en consideración las novedosas variables de Satisfactor, Intercambio, Facilitación y Comunicación (llustración 3) que modifican el modelo tradicional de Producto, Precio, Plaza y Promoción, respectivamente (Zapata, 2000).

Según Zapata, los elementos de la mezcla de mercadeo educativo deben ser denominados y conceptualizados de la siguiente manera: 


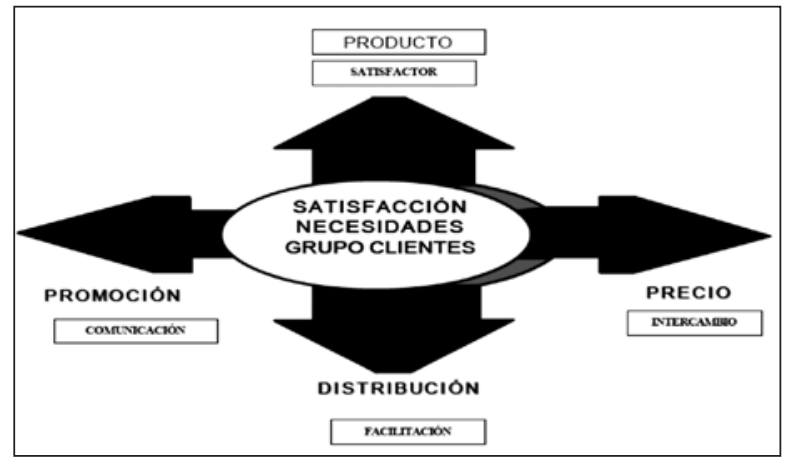

Ilustración 3. La mezcla del mercadeo educativo ${ }^{5}$

- Para el caso de los programas académicos de educación, el "producto educativo" (Satisfactor) debe comprender tanto el programa mismo como la calidad académica que debe acompañarlo (MEN, 2003).

- Por otra parte, el autor señala el precio (intercambio) del mercadeo educativo como una mediación entre la oferta académica de la universidad y las necesidades educativas de los estudiantes.

- El siguiente aspecto es la plaza (Facilitación), que está referida a la facilitad que se otorga a los estudiantes para acceder a la oferta educativa.

- Finalmente, para este autor, la promoción (Comunicación) es la estrategia de comunicación dirigida a los estudiantes y a los diferentes grupos de interés en relación con la imagen institucional, los programas académicos, las actividades desarrolladas, etc.

Por otra parte, aunque las propuestas no son abundantes, otros autores han trabajado propuestas en relación con la aplicación del mercadeo para el caso de las instituciones de educación superior. Autores como Donado (2000), Martínez (2001) o Manes (2005) concuerdan en abordar la evolución del mercadeo y aproximarse a la posibilidad de aplicar las técnicas del mercadeo en las instituciones educativas; en sus textos desarrollan temas relacionados con el comportamiento del estudiante, la segmentación del mercado, las características de los centros educativos, el servicio educativo como producto, la distribución de los servicios, el precio y la promoción en estas instituciones, entre otros aspectos y coinciden en los numerosos beneficios que ello genera para el logro de la sostenibilidad de las organizaciones educativas, la satisfacción de los estudiantes, el desarrollo de programas académicos pertinentes y el beneficio social.

\subsection{El Modelo Integrado de Gestión de Merca- deo Educativo - "MIGME"}

En la misma dirección planteada por estos autores, con el propósito de contribuir con la construcción de un modelo analítico que permita establecer las múltiples dimensiones del servicio educativo de forma que se progrese en el nivel de análisis de las variables internas y externas que todo análisis estratégico debe considerar, se propone la ampliación del modelo planteado por Zapata (2000) a la luz del modelo extendido de siete $\mathrm{P}^{\prime} \mathrm{s}$ que Booms y Bitner han propuesto (1981) y de la mezcla modificada que enuncia Kotler. Las variables consideradas en esta revisión del modelo se mencionan en la tabla 1.

Con base en este análisis comparativo, es posible desarrollar un modelo integrado que incorpore todas las dimensiones de análisis identificadas y que guarde relación con el tipo de organización en la que se pretende implementar, la organización de servicios educativos. Para avanzar en la adaptación y complementación del modelo existente, a continuación se describen cada uno de los criterios a considerar en la propuesta:

- Satisfactor - Cliente: Como se mencionó, el satisfactor ("producto educativo") debe tener en cuenta el programa académico en si mismo pero también la calidad académica asociada a este de forma que aquí deben considerarse factores como el reconocimiento de los docentes, el título otorgado por la institución, los convenios interinstitucionales, las prácticas empresariales, la flexibilidad curricular, la infraestructura de la institución, los servicios de bienestar universitario, etc. En este aspecto es fundamental considerar en primer lugar los

5 FUENTE: Zapata (2000, 4). 
Tabla 2. Variables para la ampliación del modelo de mezcla de mercadeo educativo ${ }^{6}$

\begin{tabular}{|c|c|c|c|c|}
\hline $\begin{array}{l}\text { MODELO DE } \\
\text { McCarthy } \\
\text { (Borden) } \\
\text {-PRODUctos- }\end{array}$ & $\begin{array}{c}\text { MODELO DE } \\
\text { BOOMS Y BITNER } \\
\begin{array}{c}\text { PRODUCTOSY } \\
\text { SERVICIOS- }\end{array}\end{array}$ & $\begin{array}{l}\text { MODELO DE } \\
\text { PORTER } \\
\text { (Lauterborn) } \\
\text {-SERVICIOS- }\end{array}$ & $\begin{array}{l}\text { MODELO DE } \\
\text { ZAPATA } \\
\text {-EDUCACION- }\end{array}$ & $\begin{array}{c}\text { MODELO } \\
\text { INTEGRADO DE } \\
\text { GESTIÓN DE } \\
\text { MERCADEO EDUCATIVO } \\
\text { - MIGME } \\
\text {-SERVICIOS EDUGATIVOS. } \\
\end{array}$ \\
\hline Producto & Producto & Cliente & Satisfactor & Satisfactor \\
\hline Precio & Precio & Costo & Intercambio & Intercambio \\
\hline Plaza & Plaza & $\begin{array}{l}\text { Conveniencia } \\
\text { Comodidad }\end{array}$ & Facilitación & Facilitación \\
\hline \multirow[t]{4}{*}{ Promoción } & Promoción & $\begin{array}{l}\text { Comunicación } \\
\text { Comunidad }\end{array}$ & Comunicación & Comunicación \\
\hline & Personas & & & $\begin{array}{l}\text { Miembros intervinientes } \\
\text { de la comunidad } \\
\text { académica }\end{array}$ \\
\hline & Procesos & & & Procesos Académicos \\
\hline & Evidencia Física & & & $\begin{array}{c}\text { Infraestructura física } \\
\text { e Intangible }\end{array}$ \\
\hline
\end{tabular}

deseos y las necesidades de su "cliente" antes de proceder a "elaborar" la oferta educativa, es decir, debe consultar primero las demandas que la sociedad tiene, los requerimientos del sector productivo y las necesidades de formación de los estudiantes, entre otras.

- Intercambio - Costo: Siendo este aspecto el que media entre la oferta académica de la institución y las necesidades educativas de los estudiantes y de la sociedad, debe hacer referencia tanto al valor que pagan los estudiantes por concepto de inscripción, matrícula, derechos de grado, etc., como también a los costos no monetarios asociados al proceso de formación: seguridad del sector, tiempos de traslado y costo de desplazamiento, entre otros. En la lógica del sistema educativo, la preocupación debe ser el planteamiento de alternativas que les permitan a los ciudadanos, con algún tipo de restricción económica, acceder a los servicios de formación de la institución (valor de la matrícula, facilidad de transporte, programas de becas, programas a distancia, entre otras). Por supuesto, en el caso de la organización universitaria de carácter estatal, esta preocupación debe ser aún mayor pues este criterio debe hacer aún más fácil el acceso al sistema educativo. En este caso, el estado contribuye de manera directa en el proceso garantizando que el estudiante asuma como valores de intercambio-costo solo aquellos que él estaría en capacidad de pagar y en una cuantía que estaría relacionada con su situación particular. Este sería un ejemplo del real acercamiento de la oferta educativa a las necesidades de formación de los estudiantes y por tanto, de la reducción significativa de las barreras de entrada al sistema educativo (lo cual garantiza el libre acceso).

- Facilitación - Conveniencia - Comodidad: Está referida a la facilidad que la universidad otorga a los estudiantes para acceder a la oferta educativa de la institución sin importar si ella se encuentra referida a un sitio físico o no. En este aspecto se deben considerar los aspectos

6 FUENTE: Elaboración de los autores. 
relacionados con las instalaciones de la institución, el sistema de transporte para los estudiantes, los convenios sobre programas académicos impartidos en locaciones cercanas a ellos (instalaciones de empresas, hoteles, centros de convenciones, salones comunales de ciudades y municipios apartados). No obstante, aquí también se deben considerar las modalidades alternativas que la universidad pone a disposición para el encuentro entre la institución educativa y el estudiante como puede ser el caso de las bases de datos documentales, las bibliotecas electrónicas o las aulas virtuales (para el caso de la educación a distancia o para acompañar programas en modalidad presencial), siendo este último aspecto un tema de gran acogida y desarrollo gracias al soporte de plataformas tecnológicas que facilitan el acceso a los procesos de formación.

- Comunicación - Comunidad: Este elemento involucra las estrategias de comunicación dirigidas a los diferentes grupos de interés en relación con la imagen institucional, los programas académicos, las actividades desarrolladas por la institución, los programas de bienestar, etc. En esa dirección, la comunicación debe generar un flujo de información y conocimiento de doble vía (comunicación real y no solo información) de forma que se genere una relación estrecha (directa) entre la universidad y los diferentes actores externos (Universidad-Sociedad, Universidad-Estado, Universidad-Sector productivo, Universidad Aspirantes) y entre esta y los diferentes actores internos (Universidad-Docentes, Universidad-Investigadores, Universidad-Estudiantes, Universidad-funcionarios). Este aspecto puede ser desarrollado interna y externamente mediante el uso de los diferentes canales de publicidad disponibles (intranet, internet, televisión, radio, prensa, revistas especializadas, piezas de comunicación, carteleras, comunica- ciones directas, eventos de socialización, etc.). Entre las diferentes piezas que pueden ser utilizadas para el desarrollo de este aspecto por parte de las instituciones educativas se encuentran los mecanismos tradicionales ${ }^{7}$ como televisión, prensa, plegables (brochures), pendones, la publicidad exterior, la internet, las actividades de relaciones públicas (eventos, ferias escolares y asesores comerciales) o mecanismos menos tradicionales como pueden ser los relacionadas con el BTL ${ }^{8}$ (Pérez, 2002).

- Miembros intervinientes de la comunidad académica: En este aspecto se hace referencia a la identificación de los individuos y los grupos que intervienen directamente en la prestación del servicio educativo. Esta identificación de los actores que participan en ese proceso es fundamental para establecer las características del servicio, la calidad en la prestación, la disonancia generada por la cantidad de actores, etc. Aquí también se pueden encontrar a los directivos, funcionarios, docentes, investigadores y consultores, estudiantes, organizaciones, entre otros, aunque no considerados en su rol de miembros de la comunidad académica sino en función del papel que desempeñan en relación con el servicio mismo (calidad en la respuesta a las diversas demandas ya señaladas).

- Procesos Académicos: Estos procesos apuntan a establecer la forma como se encuentran organizadas y encadenadas las actividades que la universidad desarrolla para poder diseñar, ofrecer, acompañar y evaluar su servicio de educación desde la determinación de los requerimientos existentes (demandas sociales) hasta la satisfacción de dichos requerimientos (uso del servicio). En este elemento tienen relación los aspectos referidos a los procesos de certificación institucional en el tema de calidad tanto en las universidades "privadas" (ISO's) como en

Estos mecanismos tradicionales también son denominados ATL (Above The Line) y consisten en el uso de mecanismos de comunicación masiva para impactar al público de manera general.

8 BTL (Below The Line) consiste en mecanismos no tradicionales que pretenden comunicación directa con el segmento que se pretende abordar. No solo incluye la venta personal, telemercadeo o el correo directo sino cualquier otro medio ingenioso y creativo que llegue más directamente a un nicho de mercado determinado. 
las universidades estatales (ISO's - NTC GP). Asimismo, este aspecto incluye, de facto, algunos criterios que se encuentran dentro de los requerimientos para el Registro Calificado de los programas (CONACES) o los lineamientos para la Acreditación de programas académicos (CNA).

- Infraestructura física e Intangible: En lo que se refiere a este aspecto, se consideran todas las condiciones del ambiente organizacional que pueden propiciar el adecuado desempeño de la función social (pública) de la universidad. Estos aspectos pueden ser tangibles como las aulas, los laboratorios de clase, la biblioteca, las zonas verdes, los espacios recreativos, las sedes de la universidad, el tamaño del campus, la disponibilidad de equipos, las diferentes unidades académicas, las oficinas administrativas, los laboratorios de investigación, la cantidad y calidad de los grupos de investigación, la existencia de un centro de extensión, los consultorios profesionales, etc. Sin embargo, estos aspectos también pueden ser intangibles si están referidos a la estructura orgánica de la universidad, el clima organizacional, el carácter laico o confesional de la institución, la cultura institucional, la plataforma virtual, las bibliotecas digitales, la seguridad de la institución, la intensidad de la programación académica, las franjas horarias de clase, el costo de los servicios complementarios, la vocación investigativa de la institución, el nivel de formación de los docentes, los tipos de labores asignadas a docentes e investigadores, la veracidad en la distribución de tiempos en las asignaciones académicas, el modelo pedagógico utilizado, el enfoque curricular de los programas, la vocación de trabajo social de la universidad, entre otras.

Para resumir, el modelo integrado de mercadeo para los servicios educativos consideraría entonces las dimensiones que se señalan gráficamente en la Ilustración 4.

Estas discusiones sobre las metodologías del mercadeo, aplicadas al sector servicios, evidencian no solo una cuestión de orden instrumental sino que implica, como se mencionó previamente, una revisión conceptual, analítica y lingüística del tema de manera que las acciones de mercadeo no se asimi-

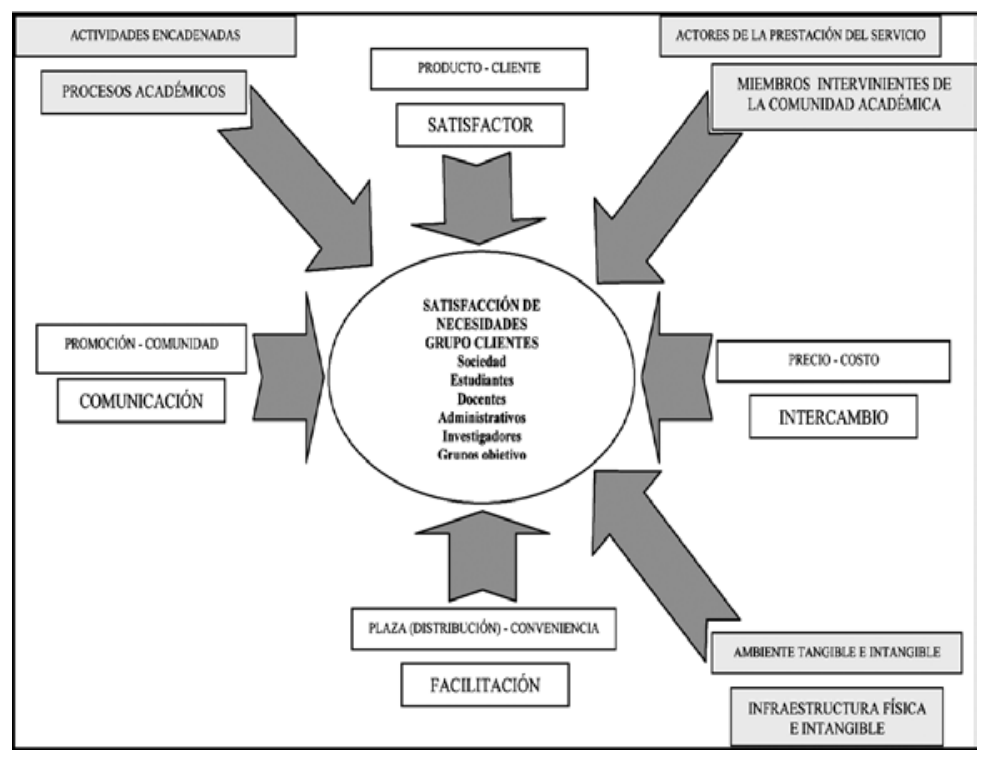

Ilustración 4. Modelo Integrado de Gestión de Mercadeo Educativo - MIGME9

9 Elaboración de los autores. 
len al simple intercambio comercial sino que refleje las acciones propias de la organización educativa en términos de su función social y su carácter de organización no empresarial.

Esa revisión no es inocua, en realidad esta discusión puede estar en la base de las problemáticas de las organizaciones educativas, en cuanto a los resultados que presentan en términos de su razón de ser y su condición de existencia (cuestiones que ya se han hecho manifiestas en apartes previos) (Sanabria, 2006). Si no existe un cambio en la aproximación conceptual y en el lenguaje empleado para trabajar con las organizaciones educativas se corre el riesgo de transformar esta institución en una organización empresarial más que tiene fines más cercanos al interés particular que a su función social. Esta apreciación no es caprichosa pues ya se ha evidenciado que la vida social (y la realidad organizacional) se construye a partir de los significados que culturalmente ha creado el ser humano (semiótica) ${ }^{10}$ y a través del sentido que se le da a los términos que ha elaborado el lenguaje (semántica) ${ }^{11}$.

En términos de los impactos que esta realidad lingüística tiene en las organizaciones, autores como Zea han manifestado:

\section{"Que sólo en actos del lenguaje que cum- plen ciertas formalidades se basa la cons- trucción de la realidad de las empresas, pero no sólo de ellas" (Zea, 2004, 33).}

Asimismo, si se quiere avanzar en la problemática planteada en cuanto se refiere específicamente al mercadeo, también existen reflexiones sobre este particular relacionadas con el resultado de la producción: el producto; en esa dirección Góngora muestra al producto como un símbolo creado por la cultura y afirma que:
"Los procesos de producción, uso, intercambio y consumo de productos, constituyen, en parte, la acción cotidiana del hombre, de su existencia. Los productos forman parte de su cotidianidad y reciben de ésta una gran carga de sentido. Es por ello que se constituyen, como el hombre mismo, en símbolo de dicha cotidianidad" (Góngora, 2005).

Sin querer profundizar, en este escrito, sobre el tema señalado, lo que se quiere enunciar es que la adaptación del lenguaje del mercadeo tradicional al mercadeo de servicios educativos (y otros servicios de orden social) es esencial para el adecuado desarrollo de las organizaciones educativas en tanto permita el cumplimiento de su función social (pública). Por ello, en este aparte se han tratado de usar las herramientas existentes, en el mercadeo tradicional, en el mercadeo de servicios y en el mercadeo de servicios educativos, para adaptar los conceptos y acercar el lenguaje de la disciplina a los requerimientos de este tipo particular de organización.

De esta forma, cuando se trabaja el modelo propuesto para el mercadeo educativo no se usan el término de producto o cliente sino de satisfactor, se cambia precio por intercambio, se modifica plaza por facilitación o conveniencia, se cambia promoción por comunicación o comunidad, se incorporan la comunidad académica, los procesos académicos y la infraestructura física e intangible de la institución en la prestación del servicio. De la misma manera, en el caso de las organizaciones educativas podemos ver la transformación del lenguaje al manifestar la importancia de la gestión de mercadeo en cuanto se refiere a dar respuesta al contexto ("orientación al mercado"), a desarrollar estrategias de mercadeo acordes con las necesidades y expectativas de los aspirantes ("un grupo objetivo"), a atender los re-

10 La semiótica estudia los signos en la vida social (Según la Real Academia de la lengua). De la misma manera estudia el significado de las representaciones simbólica que se construyen en el ámbito social.

11 La semántica estudia lo relativo a la significación de las palabras (Según la Real Academia de la lengua). Este significado de las palabras se construye también a partir del lenguaje que el humano culturalmente ha determinado.

12 El Custom Relationship Management - CRM consiste en una estrategia de la organización en la cual centra sus esfuerzos en el conocimiento cercano de sus clientes, normalmente mediante soluciones tecno lógicas, con el fin de establecer una relación muy estrecha con él y generando compromisos de largo plazo. 
querimientos del sector productivo o el estado ("grupos de referencia"), a responder a las necesidades de los miembros de la comunidad académica ("clientes internos") y a crear servicios que respondan a las demandas de la sociedad ("cliente final"), entre otros (Ilustración 2 y Ilustración 4).

En conclusión, mientras que se hagan las adaptaciones que exigen los fines de cada tipo de organización educativa y siempre que se respete su connotación en términos de servicio público, se hace explícito que el mercadeo educativo también puede hacer uso de técnicas similares a las utilizadas en el mercadeo de bienes o servicios (la investigación de mercados, la promoción, la publicidad, el telemercadeo, el mailing, las relaciones públicas, el uso de bases de datos o incluso el CRM ${ }^{12}$ (Curry \& Curry, 2002), con el propósito de satisfacer las demandas de la comunidad en términos de formación, mejorar su calidad de vida, atender a los requerimientos de la industria y en general contribuir con el desarrollo de la sociedad. Esto podría constituirse entonces en el fin teleológico del mercadeo y específicamente del mercadeo de servicios educativos.

\section{La gestión educativa y las herramientas de mercadeo}

Dado el enfoque conceptual establecido previamente, y el marco contextual existente para las organizaciones educativas, se ha hecho hincapié en la necesidad de fortalecer los procesos de la gestión educativa para el desarrollo social de las naciones, en este caso a partir del uso adecuado de las herramientas mercadológicas y específicamente del modelo integrado de mercadeo de servicios educativos que se propone. En ese sentido, con el fin de clarificar el papel que el mercadeo desempeña dentro de la gestión educativa y el desarrollo de las herramientas que se realiza en el presente apartado, en la Ilustración 5 se muestra la relación existente entre estos dos modelos.

Por otra parte, entendiendo el marco general en el que el mercadeo educativo se inscribe, a continuación se describen y contextualizan algunas de las herramientas mercadológicas que se señalaron como fundamentales para el adecuado desarrollo de la dimensión de mercadeo dentro de la organización educativa, a saber, la investigación de mercados y el plan de mercadeo.

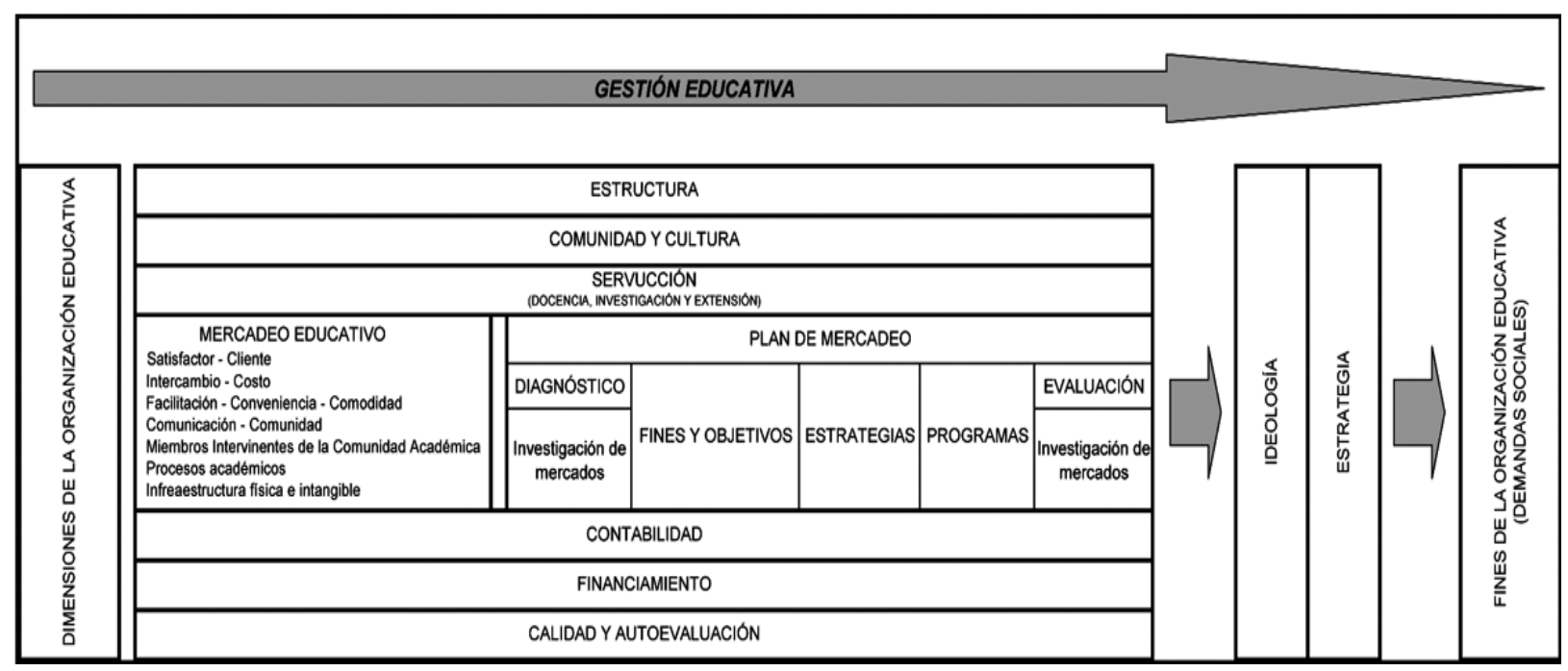

Ilustración 5. Modelo de gestión educativa ${ }^{13}$

13 Elaboración de los autores. 


\subsection{La investigación de mercados}

La Investigación de Mercados, es una de los instrumentos del mercadeo más importantes como mecanismo de identificación de las demandas sociales ya especificadas. Esta herramienta ha sido definida por la Asociación Americana de Mercadeo "AMA" como la:

"Recopilación sistemática, registro y análisis de los datos acerca de los problemas relacionados con el mercado de bienes y servicios" (Muñiz, 2008).

Y su propósito es apoyar la toma de decisiones de mercadeo. Por su parte, Carl McDaniel y Roger Gates definen la investigación de mercados como:

"La función que enlaza al consumidor, al cliente y al público con el vendedor a través de información, una información que se utiliza para detectar las oportunidades y problemas de mercadeo; para generar, refinar y evaluar las acciones de mercadeo; para observar el comportamiento del mercado y para mejorar la comprensión del mercadeo como proceso" (McDaniel \& Gates, 2005, 5-6).

Así mismo, Trespalacios resalta la importancia de la información que brinda la investigación de mercados al afirmar que, como:

"El conocimiento es poder, en la disciplina del mercadeo se recomienda que las organizaciones se orienten a los mercados, que pongan toda la atención en comprender los pormenores de su comportamiento y tendencias. La necesidad consciente de que se precisa nueva información fomenta su búsqueda a través de diversas fuentes y medios, potenciando en ultimas la investigación de mercados" (Trespalacios, 2005,31).
En otro sentido, Eyssautier de la Mora explica que todas las decisiones importantes de una organización se basan en la información que provee la investigación de mercados. Esto se presenta gracias a que ella permite la reducción significativa de la incertidumbre existente y a que facilita el proceso general de toma de decisiones (Eyssautier de la Mora, 2006, 25). Por ello, para la adecuada gestión de las organizaciones de educación superior es necesario establecer un marco general que oriente el diseño de sus investigaciones de mercado. Por supuesto, este marco general implica tomar como referente un modelo mercadológico, como cualquiera de los señalados previamente, de forma que la información que se recopile y se trabaje posteriormente brinde información suficiente sobre las diferentes dimensiones que dicho modelo contempla, aunque como ya se mencionó, siempre es adecuado realizar en él una seria adaptación al sector educativo. En este caso, consideramos importante que la investigación de mercados tenga en cuenta los aspectos de: Satisfactor - Cliente, Intercambio - Costo, Facilitación - Conveniencia - Comodidad, Comunicación - Comunidad, Personas, Procesos y Evidencia física.

Dado lo anterior, se puede afirmar que es conveniente que toda investigación relacionada con mercadeo educativo, dentro del proceso de consulta de las múltiples fuentes de información, permita una identificación clara de los aspectos específicos del medio, al menos en esas siete perspectivas. En esa exploración, una fuente de gran importancia para recaudar la información señalada está referida a las estadísticas que en materia de educación el Ministerio de Educación Nacional recaba y divulga, de manera detallada y desagregada, sobre instituciones educativas, programas académicos, población estudiantil, estadísticas sobre niveles de formación, información sobre carreras técnicas, programas tecnológicos y carreras universitarias, especializaciones, maestrías y doctorados, así mismo, es necesario acudir a las estadísticas sobre educación superior por áreas de conocimiento y por áreas geográficas ${ }^{14}$ y en general, al Sistema Nacional de Información de

14 Este tipo de información por áreas geográficas se encuentran en las estadísticas sectoriales determinadas por el Ministerio de Educación Nacional. Disponible en: http://snies.mineducacion.gov.co/men/index.htm 
Educación Superior. En el caso colombiano se pueden consultar también los reportes del DANE donde podemos encontrar información sociodemográfica sobre la población e índices sobre educación ${ }^{15}$.

Por todo ello se puede resaltar la importancia estratégica que las investigaciones de mercado tienen para la adecuada gestión de los administradores educativos en cuanto les permite conocer variables externas relacionadas con las tendencias nacionales e internacionales de la educación, las ofertas académicas de otras instituciones, las preferencias en cuanto a programas y las diversas necesidades de los estudiantes (tipo de formación, perfil de formación, convenios interinstitucionales, actividades de bienestar universitario, etc.). A nivel interno esta herramienta permite medir las variables internas asociadas a la satisfacción de los estudiantes actuales, el compromiso de la comunidad académica en general, la percepción institucional, etc.

Estas dos dimensiones de la investigación de mercados, externa e interna, son las que van a permitir relacionar este enfoque de mercadeo con las diferentes herramientas requeridas en la actualidad para una adecuada gestión educativa, es decir, los instrumentos de la investigación de mercados deberán contribuir con la recopilación de la información que requieren las organizaciones de educación superior para responder a los requerimientos del sistema de gestión de calidad, el sistema de control interno, el sistema de gestión administrativa, el sistema de aseguramiento de la calidad de la educación superior y específicamente el sistema nacional de acreditación de programas e instituciones académicas, entre otros, de manera que apoye estos procesos y evite la duplicidad de esfuerzos y acciones.

Como se hace evidente, son múltiples las utilidades que tiene esta herramienta, no obstante, su importancia radica en el hecho de que permite el diseño de programas académicos pertinentes, la formulación de proyectos de investigación convenientes, la generación de acciones de mayor impacto social, el desarrollo de acciones de Responsabilidad Social Universitaria - RSU y el diseño de estrategias de mercadeo orientadas a mejorar la percepción de la organización educativa frente a su mercado y frente al medio social en el que está incorporada.

Por esta razón, una investigación de mercados que se encuentre inadecuadamente diseñada o no se implemente en debida forma conducirá a procesos de decisión inadecuados que terminarán afectando de manera sustancial la operación de la organización educativa y generando gravísimas consecuencias para ella y para la sociedad. En consecuencia, una inadecuada o incompleta investigación de mercados pueden generar en la organización educativa la pérdida de foco (pérdida de identidad institucional), la insatisfacción de los usuarios (mala relación con los estudiantes y la comunidad académica), la disminución de la participación en el "mercado" (incapacidad para atender la demanda social y ampliar la cobertura), el desarrollo de productos inadecuados (programas descontextualizados o proyectos de investigación sin pertinencia) y obviamente el incumplimiento con las demandas sociales en materia de profesionales íntegros que aporten al desarrollo de las organizaciones y de la sociedad.

De esta manera, la orientación de las organizaciones educativas hacia el medio ("mercado") y el uso de la investigación de mercados en la gestión educativa adquieren un papel muy importante como dinamizadores del sector, haciéndolo más competente en cuanto se refiere a la calidad de la oferta académica y a los beneficios ofrecidos (infraestructura, TICs aplicadas a los modelos pedagógicos, calidad en el servicio entre otras variables). De estos procesos se benefician tanto los estudiantes (los cuales pueden decidir y escoger la mejor oferta académica acorde con sus necesidades de formación) como también el país en su conjunto (facilitando su inserción en el mundo globalizado y la superación de los profundos problemas que afectan a la población nacional). Es

15 Para obtener información estadística nacional se puede recurrir a los informes del Departamento Administrativo Nacional de Estadística - DANE. Disponible en: http://www.dane.gov.co/daneweb_V09/index.php?option=com_content\&view=article\&id=100 \&Itemid $=75$ 
decir, si las soluciones estructurales de orden social tienen que ver con el mejoramiento del sistema educativo, como estrategia de desarrollo de los países, entonces el mercadeo educativo puede desempeñar un papel de gran importancia en ese proceso.

\subsection{El plan de mercadeo}

A pesar de la importancia de la investigación de mercados como herramienta mercadológica, esta no es suficiente para convertir la información obtenida en acciones concretas dentro de la gestión universitaria. Como ocurre en otras organizaciones, la información no puede simplemente quedarse como un referente documental sino que debe materializarse en acciones específicas que permitan el mejoramiento de la gestión educativa y por ende del sistema educativo en general. En ese sentido, se requiere de un mecanismo que permita convertir la información recabada en acciones específicas, ese es el papel del Plan de Mercadeo. En consecuencia, mediante la formulación del plan de mercadeo es que los resultados, conclusiones y recomendaciones obtenidas en la investigación de mercado se convierten en el soporte de la estrategia de las organizaciones educativas.

Según Rafael Muñiz González, en el ámbito empresarial:

"El plan de marketing es la herramienta básica de gestión que debe utilizar toda empresa orientada al mercado que quiera ser competitiva. En su puesta en marcha quedarán fijadas las diferentes actuaciones que deben realizarse en el área del marketing, para alcanzar los objetivos marcados" (Muñiz, 2008).

De forma más general, el plan de mercadeo puede ser entendido como:

"Un documento que representa una detallada formulación de las acciones necesaria para llevar a cabo el programa de mercadeo, lleva a la acción, es el manual para la implementación, la evaluación y el control de mercadeo" (Ferrel, 2006, 32).
Y se entiende que:

"Se realiza a partir del conocimiento del mercado, mediante la investigación de mercados" (Eyssautier de la Mora, 2006, 35).

Para el caso de las organizaciones educativas:

"El plan de mercadeo educativo incluye la definición del mercado meta al cual se dirige el programa educativo, y las acciones relacionadas con la denominada mezcla de mercadeo para el sector educativo: satisfactor, intercambio, facilitación y comunicación" (Zapata, 2000).

De manera que, las universidades puedan ofertar programas y servicios educativos acordes con las necesidades de la sociedad, y las organizaciones empresariales en cuanto a la formación de profesionales íntegros, con capacidad para resolver los problemas de las organizaciones y contribuir con el desarrollo del país. En suma, se puede decir que el plan de mercadeo no es solamente una importante herramienta mercadológica sino que empieza a generar vínculos esenciales con los enfoques de gestión estratégica que tanto requieren las organizaciones. Lo anterior se evidencia por cuanto el plan de mercadeo es el que permite la organización, clarificación, ponderación y esquematización de la información relacionada con el medio y que puede representar mayor trascendencia para el desarrollo de la gestión educativa en términos del establecimiento de cursos de acción para la organización de educación superior.

Por otro lado, al igual que el plan de mercadeo (junto con las demás las herramientas mercadológicas) es de gran utilidad para la gestión de la institución de educación superior, considerada de forma general, este también tiene grandes beneficios para la acción de quienes se desempeñan como administradores educativos de aquella, a saber:

- Reduce el nivel de subjetividad del decisor por lo que se genera mayor confianza en todos los actores relacionados en relación con la información disponible (la información es más real). 
- Reduce los riesgos asociados a la toma de decisiones cotidianas por cuanto las determinaciones se toman con base en criterios estratégicos.

- Facilita la planeación periódica dentro de la institución educativa y permite la comparación de su situación en un periodo determinado con periodos históricos previos.

- Reduce el número e intensidad de las desviaciones existentes entre los resultados obtenidos por la organización y los objetivos señalados inicialmente. Esto permite el monitoreo contante de la situación y una verdadera retroalimentación.

- Contribuye con el análisis estratégico permanente haciendo que las acciones implementadas correspondan con la realidad del medio, las condiciones institucionales y las finalidades de la institución.

A pesar de los beneficios generales o particulares ya mencionados, la sola existencia del plan de mercadeo no garantiza su aporte a la gestión de cualquier organización; para que este cumpla su papel se debe desarrollar de forma estructurada, clara y organizada. En ese marco, se han desarrollado múltiples aproximaciones en pos de establecer el número de pasos que se debe considerar para el desarrollo adecuado de un plan de mercadeo, sin embargo, para los propósitos que se pretenden en la organización educativa, cualquiera de las aproximaciones puede ser legítima siempre que incorporen los procesos comprendidos entre el diagnóstico organizacional (investigación de mercados) y los medios para evaluar su implementación. Por ello, solo con propósitos ilustrativos, se muestra la propuesta desarrollada por Pinilla \& Martínez que plantea un proceso de tres etapas y siete fases para el desarrollo del plan de mercadeo (Ilustración 6).

Sin embargo, con el propósito de simplificar el modelo de plan de mercadeo educativo, aunque sin perder ninguna dimensión del análisis, para el caso del mercadeo educativo se propone una metodología que incorpore las cinco etapas que se señalan en la Ilustración 7.

- La primera etapa es analizar la situación en la que se encuentra la organización lo cual requiere de un diagnóstico de la situación, tanto del microambiente como del macroambiente de la organización. Para ello, el analista puede utilizar cualquier herramienta de diagnóstico (como el DOFA, La Matriz BCG, La Matriz ProductoMercado, entre otras) que le permita conocer las oportunidades y amenazas que se le pueden presentar a la organización educativa en el medio así como también las fortalezas y las debilidades que ella tiene para enfrentarlas.

- La segunda etapa del plan de mercadeo educativo se refiere a los propósitos últimos (finalidad) de la organización educativa y a la determinación de los objetivos (cualitativos y cuantitativos) que ella tiene para un período de

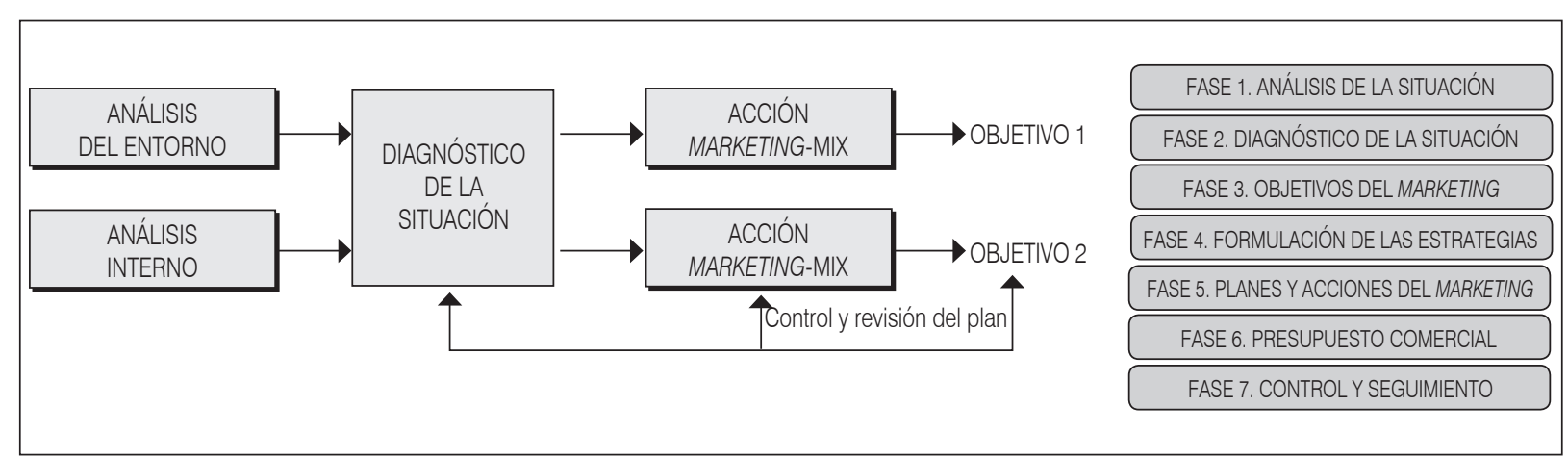

Ilustración 6. Etapas y fases de un plan de marketing ${ }^{16}$

16 Adaptado de Pinilla, J. \& Martínez J. "CEO Proyecto Empresarial”. Mc Graw Hill. 
tiempo establecido. Es decir, este componente establece lo que se quiere conseguir para la organización educativa como puede ser el hecho de ser referida socialmente por su calidad académica, aumentar la cobertura, abrir nuevos programas académicos, realizar convenios interinstitucionales, etc.

- En tercera instancia se deben definir los cursos de acción que se pueden establecer para obtener los propósitos y objetivos planteados. Para esto se deben determinar las estrategias que se requiere la organización educativa para cumplir sus fines y los medios necesarios que ellas implican.

- En cuarto lugar, se deben traducir las estrategias y tácticas a programas y planes de acción (despliegue estratégico) de forma que quede incorporado el presupuesto, todos los costos asociados y los resultados previstos para cada una de ellas (indicadores). Allí se detallan los costos de implementación del plan y los ingresos que se espera recibir con el fin de determinar la sostenibilidad económica y académica de la misma.

\section{PLAN DE MERCADEO EDUCATIVO}

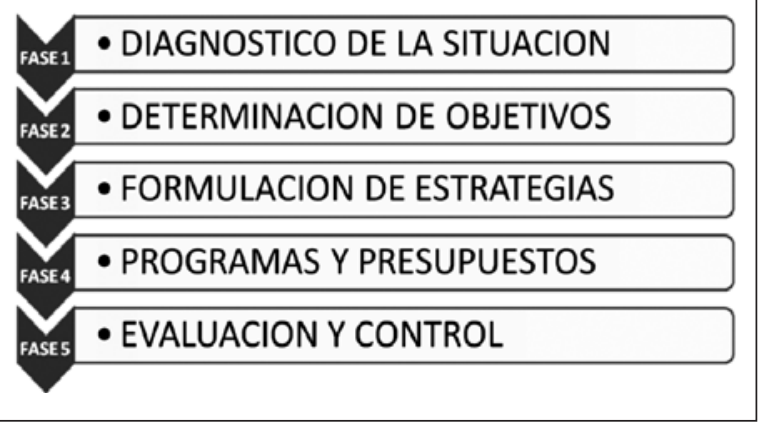

Ilustración 7. Etapas para el desarrollo de un plan de mercadeo educativo ${ }^{17}$

- Finalmente, la quinta etapa implica establecer los medios de evaluación y control que se re- quieren para evidenciar el nivel de cumplimiento de los resultados, las tácticas, las estrategias y los fines (cronogramas de ejecución de actividades, Tablas de asignación de recursos, indicadores de gestión por proceso, etc.) y por tanto, las acciones de mejoramiento que permitan su posterior cumplimiento.

De acuerdo con lo señalado, el plan de mercadeo educativo es útil tanto para el cumplimiento de los propósitos establecidos para la organización general como también para el logro de los objetivos de sus facultades, programas académicos, unidades académicas y el desempeño de la labor de quienes se encuentran encargados de la gestión de las mismas. La ausencia de un plan de mercadeo implica la pérdida del control sobre la operación de la organización educativa, y por tanto, la somete a las convulsiones del medio.

A pesar de todo lo señalado, la existencia del plan de mercadeo educativo no necesariamente garantiza el éxito de la organización de educación pues, como sabemos, las realidades sociales desbordan la capacidad de los modelos por reflejarlas. En ese sentido, el plan de mercadeo debe ser implementado con mucha prudencia, haciendo una revisión constante del contexto interno y externo en que se ejecuta, designando a los diferentes participantes las actividades concretas que deben desempeñar como parte del mismo y otorgando mayores niveles de participación a los actores que hacen parte de la institución educativa.

Para finalizar, en el desarrollo del documento se ha hecho evidente que tanto los conceptos como los instrumentos del mercadeo en general, previamente adaptados a las condiciones y características de las organizaciones de servicios y más concretamente a las organizaciones educativas, son medios esenciales para este tipo de organizaciones en la medida en que permiten la oferta adecuada de programas académicos, avala la pertinencia de sus servicios, garantiza la atención a las necesidades de sus diversos actores y asegura el verdadero impacto social que le corresponde.

17 Elaborado por los autores. 


\section{Comentarios finales}

La gestión de mercadeo es fundamental para la existencia de toda organización pues es la que puede garantizar el cumplimiento de su función social y económica. Por ello, la función de mercadeo es esencial para que la organización educativa cumpla los propósitos que la sociedad le ha otorgado.

Existen aproximaciones al mercadeo de orden meramente empresarial (transaccional) que lo consideran como un medio para lograr el intercambio comercial, sin embargo, otras aproximaciones al mercadeo son más amplias al considerar el mercadeo como una función que media entre las necesidades individuales y sociales y la organización que se encuentra en capacidad de satisfacerlas.

La organización educativa, como una organización de gran relevancia social, debe trascender la visión transaccional del mercadeo con el fin de que pueda cumplir su finalidad específica. El mercadeo surge como una función empresarial que permite la ubicación de los productos elaborados (tangibles) en el mercado. Como consecuencia de contextos económicos difíciles, el crecimiento del sector servicios, la oferta de servicios profesionales de manera personal y la desregulación de algunos servicios, el mercadeo empezó a ser usado de manera importante dentro del sector de servicios.

La aplicación del mercadeo tradicional (de productos) en el sector servicios ha implicado una reconceptualización y una adaptación lingüística dentro del mismo para acomodarla a las especificidades del sector, tal es el caso de la adaptación de los conceptos y lenguaje basado en el producto a aquellos que requiere un enfoque centrado en el cliente. No obstante, es importante que esta revisión se siga realizando para adaptar el lenguaje a un contexto no transaccional (organizacional) y a las especificidades de cada servicio, en este caso específicamente para las organizaciones educativas.

La educación puede ser considerada como un servicio por dos razones. La primera es por la responsabilidad que la sociedad la ha otorgado a este tipo de organizaciones en función del impacto que tiene en el desarrollo humano, social, cultural, económico de la misma - Es un servicio de carácter público y social-. La segunda se refiere a que comparte las características de los servicios, es decir, la intangibilidad, su consumo en el mismo momento en que se crea, no se puede repetir y no es almacenable, entre otras.

El contexto educativo colombiano presenta múltiples dificultades en cuanto no ha podido responder adecuadamente a las demandas sociales existentes. Esta situación que se evidencia en las estadísticas del sector educativo puede ser producto de la incapacidad de las organizaciones educativas de identificar los actores involucrados y priorizar sus múltiples necesidades.

La educación superior tiene como fin formar profesionales íntegros que sirvan al desarrollo de las organizaciones y la sociedad en general. Por tanto, las organizaciones del sector educativo deben orientar su gestión mercadológica a satisfacer las necesidades de la sociedad y de las organizaciones mediante programas y servicios académicos de alta calidad. Para desarrollar el mercadeo en el sector educativo se deben tener en cuenta diferentes fuentes de información, las cuales coinciden en la necesidad e importancia de ofrecer programas académicos de alta calidad y con pertinencia -en términos de las necesidades mencionadas-.

El mercadeo de servicios educativos es una adaptación del mercadeo de servicios (por ello también del mercadeo de productos) que le sirve a las instituciones educativas para el diseño de estrategias que permitan ampliar la cobertura estudiantil en el marco ético de la educación, satisfacer los diferentes intereses de los miembros de la comunidad académica, planificar, desarrollar y divulgar los programas académicos, promover la imagen institucional de las organizaciones educativas y optimizar la calidad del servicio educativo de acuerdo con las necesidades de los estudiantes, sus miembros, sus familias, las organizaciones y la sociedad.

Después de la transición del mercadeo centrado en el producto al mercadeo centrado en el cliente, algunos autores han planteado también modelos de 
aplicación del mercadeo de servicios a las especificidades de las organizaciones educativas. Esta aplicación debe contemplar las adaptaciones conceptuales, analíticas y lingüísticas que permitan deificar la acción de la organización educativa. Con esa salvedad, el mercadeo de servicios es una ampliación del concepto de mercadeo tradicional que podría permitirle utilizar las mismas herramientas.

Debido a los constantes cambios en el medio educativo se requiere cada vez más de herramientas de gestión similares a las usadas en otros sectores. El mercadeo educativo es una alternativa para las organizaciones educativas ante la creciente oferta de programas académicos y las necesidades de formación requeridas. De igual manera, es útil como medio de integración entre los diferentes sistemas de gestión que requiere la organización educativa actualmente.

En el mercadeo educativo, los modelos propuestos pueden ser de gran utilidad para facilitar la identificación de las variables más significativas dentro de un análisis del medio interno y externo de la organización. Su implementación en las organizaciones educativas facilita el desarrollo de investigaciones de mercado pertinentes que reflejen los problemas y necesidades en cuanto se refiere a demandas educativas, tendencias en educación, ofertas académicas de otras instituciones, etc. Con base en dichos estudios es posible diseñar la oferta del servicio educativo que mejor satisfaga dichas necesidades.

El plan de mercadeo es un instrumento esencial en toda institución educativa puesto que facilita la oferta eficaz de los programas académicos. El plan de mercadeo educativo incluye las mismas variables que se han analizado para la investigación de mercado pues corresponde a las categorías que la mezcla de mercadeo de servicios educativos ha planteado. Su propósito es permitir el desarrollo de la estrategia de la organización educativa, la concreción de la estrategia organizacional en planes de acción específicos y facilitar la gestión educativa de quienes han asumido la labor de dirección en estas organizaciones

Queda mucho camino por recorrer en nuestro país en cuanto a la orientación de las organizaciones del sector educativo hacia un modelo de mercadeo pertinente para este tipo de organización. El escenario más adecuado sería aquel donde las organizaciones educativas realicen constantes investigaciones de mercado y dispongan de un plan de mercadeo educativo que, debidamente elaborado, sirva de guía para proporcionar satisfacción a las demandas sociales.

\section{Referencias}

Asociación Colombiana de Universidades - ASCUN (2007). POlíticas y Estrategias para la Educación Superior de Colombia 2006-2010. Corcas Editores Ltda. Disponible en: http:// www.ascun.org.co/documentos/educacion2006-2010.pdf

Berry, L. (1983). Relationship marketing of services: Growing interest, Emerging Perspective. Journal of the Academy of Marketing Science, 23: 236-245.

Booms, B. \& Bitner, J. (1981). Marketing Strategies and Organizational Structures for Service Firms. En Marketing of Services. J. Donnelly y W. George (eds). Chicago, IL: American Marketing Association, pp.47-52.

Borden, N. (1964). The concept of the Marketing Mix. Journal of Advertising Research, Vol. 4, Junio de 1964, pp. 197-208.

Brown, J.; Lusch, R. \& Nicholson, C. (1995). Power and Relationship Commitment: their Impact on Marketing Channel Member Performance. Journal of Retailing, vol. 71, N. 4, pp. 363-392.

Caetano, A. \& Gonzalo, N. (2003). Tesis doctoral - Marketing en los servicios de educación: modelos de percepción de calidad. Universidad Complutense de Madrid, Facultad de Ciencias Económicas y Empresariales. Disponible en: http:// eprints.ucm.es/tesis/cee/ucm-t26770.pdf

Castells, M. (1997). La era de la información: economía, sociedad y cultura. Madrid: Editorial Alianza.

Congreso de la República de Colombia (1992). Ley 30 de Diciembre 28 de 1992: Por el cual se organiza el servicio público de la Educación Superior. Disponible en: http://www.cna. gov.co/1741/articles-186370 ley 3092.pdf

Congreso de la República de Colombia (2008). Ley No. 1188 de Abril 25 de 2008: "Por la cual se regula el registro calificado de programas de educación superior y se dictan otras disposiciones" Disponible en http://www.mineducacion.gov co/1621/articles-159149 archivo pdf.pdf

Consejo Nacional de Acreditación. ¿̇Cuál es la situación actual de maestrías y doctorados en Colombia? ¿Cómo se compara con los posgrados en otros países? Disponible en: http:// www.cna.gov.co/1741/article-187381.html

Curry, J \& Curry, A (2002). Customer Relationship Management: "Cómo implementar y beneficiarse de la gestión de las relaciones con los clientes". Barcelona: Gestión 2000.

Dans, Enrique. CRM, Customer Relationship Management. Disponible en: http://profesores.ie.edu/enrique_dans/download/crm.pdf

Departamento Administrativo Nacional de Estadística - DANE (2010a). Índice de la Educación Superior Privada - ICESP Variación anual total y por tipos de institución (1998 - I se- 


\section{UN ENFOQUE DE MERCADEO DE SERVICIOS EDUCATIVOS PARA LA GESTIÓN DE LAS ORGANIZACIONES DE EDUCACIÓN SUPERIOR EN COLOMBIA: EL MODELO MIGME}

mestre de 2010). Disponible en : http://www.dane.gov.co/ daneweb_V09/index.php?option=com_content\&view=articl e\&id $=100$ \&ltemid $=75$

Departamento Administrativo Nacional de Estadística - DANE (2010b). Índice de Precios al Consumidor Base 2008 (IPC) Variaciones Porcentuales (1995-2010). Disponible en: http:// www.dane.gov.co/daneweb_V09/index.php?option=com content\&view $=$ article\&id $=103 \&$ ttemid $=76$

Departamento Administrativo Nacional de Estadística - DANE. Disponible en: http://www.dane.gov.co/daneweb V09/index.php?option $=$ com_content\&view $=$ article\&id $=1 \overline{00} \& \mathrm{Item}$ $\mathrm{id}=75$

Donado, G. (2000). Introducción al Mercadeo Educativo. Colombia: Ediciones Uninorte.

Educación Compromiso de Todos. Educómetro. Disponible en: http://www.educacioncompromisodetodos.org/scripts/educometro. php?tema $=1$

Eiglier, P. \& Langeard, E. (1989). Servucción: el marketing de los servicios. España: Editorial McGraw Hill.

Eyssautier, M. (2006). Investigación de Mercados: enfoques, sistemas, información, procesos y proyectos. México: Trillas.

Fernández, R. (2002). Fundamentos de Mercadotecnia. México: Editorial Thompson.

Gazzola, A. \& Didriksson, A. (2008). Estudio Tendencias de la Educación Superior en América Latina y el Caribe Editorial: Instituto Internacional de la UNESCO para la Educación Superior en América Latina y el Caribe, IESALC. Disponible en: http://www.ufgd.edu.br/esai/esaiinforma/cursos/ToRProyectoTendencias_Sintesis.pdf

Góngora, A. (2005). La dimensión simbólica del mundo de los productos: El mundo productual. En: Revista Colombiana de Marketing - Revista de la Facultad de Ingeniería de Mercados de la Universidad Autónoma de Bucaramanga, Año $4 \mathrm{~N}^{\circ}$ 6 Octubre de 2005. pp.46-50.

Gronroos, Chistian (1990). Service Management and marketing. Managing the moments of truth in service competition. Lexinton Books.

Gummeson, Evert (1995). Why Reationship Marketing is a Paradigm Shift: Some conclusions from the 30R Approach. Management decision, Vol. 35, No. 3-4. MCB University Press Ltd.

Ibarra, O. (2004). Algunos aportes sobre las relaciones entre universidad y sociedad. En: Colección Conferencias - Número 3. Bogotá: Editorial Bonaventuriana.

Jobber, David \& Fahy, John. (2007). Fundamentos de Marketing. $2^{\mathrm{a}}$ edición. Madrid: Editorial McGraw Hill.

Jul, V. \& Carlos G. (2005). Universidad, educación y crítica de la globalización. En: Revista Mediaciones, 5: 43-52.

Kinner \& Taylor (2005). Investigación de Mercados. 6a edición. Editorial McGraw Hill.

Kotler, P \& Armstrong, G (1998). Fundamentos de Mercadotecnia. $4^{a}$ edición. Editorial Prentice Hall.

Kotler, P (1999). Marketing Management: Analysis, Planning, Implementation, and Control. 9 Ed. Prentice Hall College Div.

Lamb, C.; Hair, J. \& Mc Daniel, C. (2006). Fundamentos de Mercadotecnia. $4^{a}$ edición. Editorial Thomson.

Lauterborn, B. (1990). New marketing litany: four Ps passe: Cwords take over. Advertising age. 61 (41), 26.

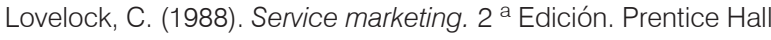
International Editions.
Manes, J. (2005a). Gestión Estratégica para Instituciones Educativas. Ediciones Granica S.A.

Manes, J. (2005b). Marketing para instituciones educativas. Ediciones Granica S.A.

Martínez, F. (2001). Introducción al Marketing Educativo. Colombia: Ediciones Uninorte.

McCarthy, J. (1960, 1975). Basis Marketing: A managerial Approach. Homewood III. Irwin.

Mc Daniel, C. \& Gates, R. (2005). Investigación de Mercados. $6^{a}$ edición. Editorial Thomson.

Mercados Business Project Innovation - Merk2. De las $4 P^{\prime}$ s a las $4 \mathrm{C}$ 's. Entrevista a Philiph Kotler. Documento disponible en http://www.merk2.com/portada/Documentacion/De\%20 las\%20cuatro\%20Ps\%20a\%20las\%20cuatro\%20Cs.pdf

Ministerio de Educación Nacional - MEN. Estadísticas sectoriales. Disponible en: http://snies.mineducacion.gov.co/men/ index.htm

Ministerio de Educación Nacional - MEN. Estadísticas Sectoriales Educación Superior. Disponible en: http://menweb.mineducacion.gov.co/info_sector/estadisticas/superior/index.html

Ministerio de Educación Nacional - MEN. Observatorio Laboral. Disponible en: http://www.graduadoscolombia.edu.co/ html/1732/channel.html

Ministerio de Educación Nacional - MEN (2002). La Revolución educativa. Disponible en: http://www.mineducacion.gov. co/1621/articles-85758 Archivo pdf1.pdf

Ministerio de Educación Nacional - MEN (2003). Decreto 2566 de Septiembre 10 de 2003: "Por el cual se establecen las condiciones mínimas de calidad y demás requisitos para el ofrecimiento y desarrollo de programas académicos de educación superior y se dictan otras disposiciones". Disponible en http://www.mineducacion.gov.co/1621/articles-86425_ Archivo pdf.pdf

Ministerio de Educación Nacional - MEN (2006a). Plan Decenal de Educación 2006-2016. Disponible en http://www. plandecenal.edu.co/html/1726/articles-140863 archivo.pdf

Ministerio de Educación Nacional - MEN (2006b). Cobertura con Calidad y Equidad. Educación Superior: Boletín Informativo No. 6 - Enero-marzo de 2006. Disponible en http://menweb. mineducacion.gov.co/educacion_superior/numero_06/portada.htm

Ministerio de Educación Nacional - MEN (2009). La articulación de la educación media con la superior y la formación para el trabajo fue socializada en toda Colombia este sábado. Disponible en http://www.mineducacion.gov.co/cvn/1665/ article-205382.html

Muñiz, A (2008). El plan de marketing de la empresa. En: marketing en el siglo XXI. $2^{a}$ edición. Editorial Centro de Estudios Financieros. Versión digital disponible en: http://www.marketing-xxi.com/el-plan-de-marketing-en-la-empresa-132.htm

Navarro, E (2002). ¿Qué es un CRM? En nuevas tecnologías de la empresa. Abril de 2002. Disponible en: http://www.masterdisseny.com/master-net/improv/0008.php3

Observatorio de la Universidad Colombiana. Cobertura de la Educación Superior en Colombia. Disponible en http://universidad.edu.co/index.php?option $=$ com_content\&task $=$ vie w\&id $=35 \&$ ltemid $=11$

Ospina, M (2006). Tesis de Grado "Meritoria": Mercadeo Educativo un Camino a la Excelencia. Especialización en Mercadeo de Servicios. Universidad Militar Nueva Granada. 
Parsons, T (1960). Structure and Process in Modern Societies. Glencoe, III: The Free Press. Citado en Etzioni, Amitai (1972). Organizaciones Modernas. México: Unión Tipográfica Editorial Hispano-Americana.

Pereira, Jorge. BTL - Marketing Bajo la Línea. En: Revista virtual Inpsicon - Investigación en Psicología del consumidor. Disponible en: http://www.inpsicon.com/elconsumidor/articulos/BTL/BTL.pdf

Pérez del campo, E (2002). Comunicación fuera de los medios: Below The Line Madrid: ESIC editorial.

Pinilla, F. M.; Martínez, J. I. \& Sangüesa, J. C. (1998). CEO Proyecto Empresarial. España: Mc Graw Hill Interamericana de España. Pág. 95.

Portafolio (2010). Aumentó la tasa de alfabetización en Colombia: en 2009 fue de 94,1\%, según estudio. 8 de Abril de 2010. Disponible en: http://www.portafolio.com.co/economia/pais/ ARTICULO-WEB-NOTA INTERIOR PORTA-7557028.html

Presidencia de la República de Colombia \& Departamento Nacional de Planeación. Visión Colombia /l Centenario 2019. Disponible en http://www.accionsocial.gov.co/documentos/207 vision2019.pdf

Rincón, F. (2009). 2009 Año de la Educación para la Innovación y la Competitividad desde la Pertinencia. Comisión Nacional de Seguimiento al Plan Decenal de Educación 2006-2016.
Disponible en: http://www.plandecenal.edu.co/html/1726/ articles-200662_archivo_pdf.pdf

Sanabria R., Pedro E. (2006). Nuevas perspectivas de la gestión: Significados en la gestión universitaria. En Colección Conferencias - Número 17. Bogotá: Editorial Bonaventuriana.

Shostack, G. Lynn (1982) How to Design a Service. En European Journal of Marketing 16: 49-63.

Shostack, G. Lynn (1992) Understanding Services Through Blueprinting. En Swartz, Teresa; Bowen, David \& Brown, Stephen. Advances in Services Marketing and Management. Greenwich: JAI Press Vol. 5, CT, pp.75-90.

Trespalacios, J.; Vasques, R. \& Bello, L. (2005). Investigación de Mercados. Editorial Thomson.

Universia (2010). Formación doctoral en Colombia. Mayo 3 de 2010. Disponible en: http://encuentros.universia.net/CO/espanol/noticia-220-informe.html

Webometrics (2009). Ranking Mundial de Universidades. Información disponible en http://www.webometrics.info/top100_ continent_es.asp?cont=latin_america

Zapata, E. (2000). Mercadeo Educativo ¿Cómo promover la oferta de instituciones y programas?. En: Revista Colombiana de Marketing. Universidad Autónoma de Bucaramanga. Año 1 $N^{\circ} 1$ Junio de 2000. Versión digital disponible en http://editorial.unab.edu.co/revistas/rcmarketing/pdfs/r11 art4 r.pdf

Zea, L. (2004). La organización como tejido conversacional. Medellín: Universidad EAFIT. 